\title{
Performance of pop-up satellite archival tags
}

\author{
M. K. Musyl ${ }^{1, *}$, M. L. Domeier ${ }^{2}$, N. Nasby-Lucas ${ }^{2}$, R. W. Brill ${ }^{3}$, L. M. McNaughton ${ }^{1}$, \\ J. Y. Swimmer ${ }^{4}$, M. S. Lutcavage ${ }^{5,8}$, S. G. Wilson ${ }^{5}$, B. Galuardi ${ }^{5,8}$, J. B. Liddle G,7 $^{6}$ \\ ${ }^{1}$ University of Hawaii, Joint Institute for Marine and Atmospheric Research (JIMAR), \\ Kewalo Research Facility/NOAA, 1125B Ala Moana Boulevard, Honolulu, Hawaii 96814, USA \\ ${ }^{2}$ Marine Conservation Science Institute, 2809 South Mission Road, Suite G, Fallbrook, California 92028, USA \\ ${ }^{3}$ NOAA/NMFS Northeast Fisheries Science Center, Virginia Institute of Marine Science, PO Box 1346, Gloucester Point, \\ Virginia 23062, USA \\ ${ }^{4}$ NOAA/NMFS, Pacific Islands Fisheries Science Center, 2570 Dole Street, Honolulu, Hawaii 96822, USA \\ ${ }^{5}$ Large Pelagics Research Center, Department of Zoology, University of New Hampshire Durham, New Hampshire 03824, USA \\ ${ }^{6}$ University of Alaska Southeast, Department of Mathematics, 1332 Seward Avenue, Sitka, Alaska 99835, USA \\ ${ }^{7}$ Liddle and Lee LLC, 609 Sawmill Creek Road, Sitka, Alaska 99835, USA \\ ${ }^{8}$ Present address: Large Pelagics Research Center, Natural Resources Conservation Department, University of
Massachusetts at Amherst and Marine Fisheries Institute, 108 East Main Street, Gloucester, Massachusetts 01930, USA
}

ABSTRACT: Pop-up satellite archival tags (PSATs) are used to chronicle or 'archive' the habitat preferences, horizontal and vertical movements, fishery interaction, and post-release mortality rates of a variety of pelagic animals. Though PSATs are valuable research tools, lower-than-expected reporting rates, early detachment, and incomplete data return remain problematic. These issues were quantified by analysis of reporting rates, retention times (i.e. the time period PSATs remained attached), and the quantity of depth, temperature, and geolocation data returned from 731 PSAT deployments on 19 species in the authors' database and 1433 PSAT deployments on 24 species taken from 53 published articles. The reporting rate of PSATs deployed by the authors $(0.79,95 \% \mathrm{CI}=0.76$ to 0.82$)$ was not significantly different from the reporting rate calculated from published studies $(0.76,95 \% \mathrm{CI}=0.74$ to 0.78). PSAT reporting rates were lowest in species undertaking large ( 1000 m) vertical excursions (logistic regression, $\mathrm{p}=0.006)$, and reporting rates have increased significantly over time ( $p=0.02)$, presumably because of better PSAT design and construction. Tag retention increased with depth range of the tagged species and pop-off latitude (Cox proportional hazards models, $\mathrm{p}<0.001$ ), suggesting that pressure (and/or temperature), biofouling, and wound infection at the insertion site of the PSAT's anchoring device influenced this parameter. The quantity of data returned by Argos satellites was affected by tag production year, programmed pop-up period, depth range, and manufacturer. Species-specific reporting rates were used to make recommendations for future PSAT sampling designs.

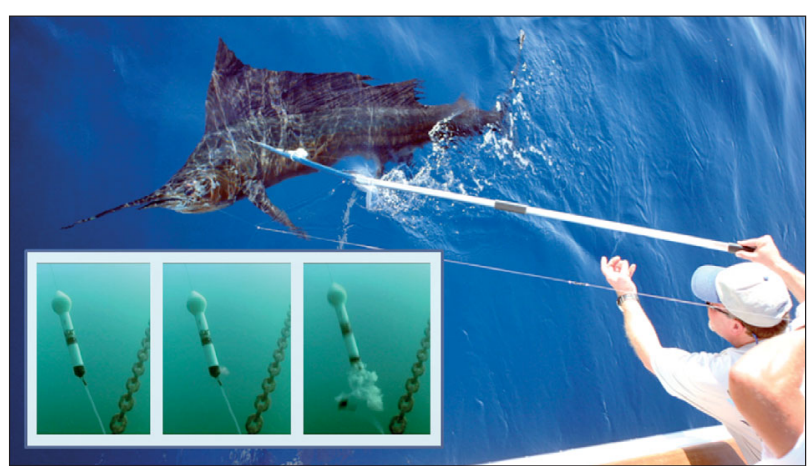

Deploying a prototype pop-up tag with explosive release (insets) on an Indo-Pacific sailfish Istiophorus platypterus.

Photos: Guy Harvey, Michael Domeier (insets)

KEY WORDS: Argos • Logistic regression - Risk • Cox proportional hazards - Meta-analysis - Odds ratio Kaplan-Meier · Survival analysis · PSAT

Resale or republication not permitted without written consent of the publisher

\section{INTRODUCTION}

Pop-up satellite archival tags (PSATs) are electronic data storage devices that are attached externally to marine animals with a tether and various anchoring devices. The various attachment methods used to affix PSATs on teleosts, other fishes, elasmobranchs, sea turtles and squid are discussed in Block et al. (1998), 
Chaprales et al. (1998), Lutcavage et al. (2001), Swimmer et al. (2002), Prince et al. (2002), Thorsteinsson (2002), Domeier et al. (2003), Gilly et al. (2006) and Epperly et al. (2007). Current-generation PSATs record data on ambient light-level irradiance from which geolocations can be calculated (Musyl et al. 2001), along with depth (pressure) and temperature. PSATs are increasingly used in marine fisheries research (Arnold \& Dewar 2001, Brill \& Lutcavage 2001, Gunn \& Block 2001, Thorsteinsson 2002, Bolle et al. 2005) to chronicle horizontal and vertical movements (e.g. Lutcavage et al. 1999, Domeier et al. 2005, Wilson et al. 2005, 2006), residence times (Domeier 2006, Domeier \& Nasby-Lucas 2008), and post-release mortality (Domeier et al. 2003, Moyes et al. 2006, Swimmer et al. 2006) of teleost, elasmobranch, and sea turtle species. Refinement of lightbased geolocation methods (Teo et al. 2004, Domeier et al. 2005, Nielsen et al. 2006, Wilson et al. 2007, Galuardi et al. 2008, Luo et al. 2008) has enhanced the utility of PSATs in marine fisheries research.

PSATs have advantages over implanted archival tags, because data are retrieved via transmission to the Argos satellite system (i.e. the tags themselves do not have to be retrieved), and the tags are able to save themselves with 'fail-safe' options. Microwave Telemetry (MT) and Wildlife Computers (WC) have taken different approaches to implement 'fail-safe' recovery features in PSATs. And in this regard, PSAT function has changed significantly since the reviews of Arnold \& Dewar (2001) and Gunn \& Block (2001). Contemporary PSATs are programmed to initiate data transmission to the Argos system under 3 conditions: (1) the PSAT remains attached until its programmed pop-up date, at which time an electrolytic breakaway pin in the nosecone corrodes, releasing the PSAT from its tether. The PSAT floats to the surface, and data transmission commences. (2) The tagged animal dies and sinks to $\sim 1200$ to $1800 \mathrm{~m}$, at which time the PSAT releases and floats to the surface (e.g. Moyes et al. 2006). In the MT tags, an electrolytic breakaway pin in the nosecone corrodes under this circumstance. With WC tags, the manufacturer supplies a mechanical unit (RD1500; RD = release device) which severs the monofilament tether at $\sim 1500 \mathrm{~m}$ depth (in current version PSATs from $\mathrm{WC}$, the device has been upgraded to RD1800). (3) With both manufacturers, if the tag experiences no significant pressure change for a programmable number of days (usually 2 to 4 d), the PSAT releases, and data transmission is initiated. Constant pressure would occur if the PSAT was floating on the surface following premature release from the animal, or if the animal died and sank to a bottom depth shallower than 1200 to $1800 \mathrm{~m}$ (e.g. Swimmer et al. 2006). Further details about the MT and WC PSATs are provided at the manufacturers' websites and in Table S1 in the supplement at www.int-res.com/articles/suppl/ m433p001_supp.pdf. The operations manual for WC PSATs used in this study is available at www.wildlifecomputers.com/Downloads/Documentation/PAT4 $\% 20$ Manual.pdf.

The fail-safe option allows researchers to identify postrelease mortality (Swimmer et al. 2002, 2006, Domeier et al. 2003, Chaloupka et al. 2004, Moyes et al. 2006, Hays et al. 2007). Ambiguity arises, however, when PSATs fail to report. Because a variety of factors may be responsible for tag failure, it is challenging to discriminate PSAT failure from subject mortality (Graves et al. 2002, Kerstetter et al. 2003, Kerstetter \& Graves 2006). Several authors commented that failure of electronic tags, including PSATs, cannot be considered synonymous with mortality (Goodyear 2002, Chaloupka et al. 2004, Hays et al. 2007).

Despite the widespread adoption of PSATs in marine fisheries research, concerns remain about their reliability and overall performance (Arnold \& Dewar 2001, Gunn \& Block 2001, Holland \& Braun 2003). The vast majority of PSATs $(\sim 80 \%)$ are shed before their programmed pop-up date (Arnold \& Dewar 2001, Gunn \& Block 2001), but factors influencing PSAT reporting rates and intermittent data transmission to Argos, and the time PSATs remain attached, are not well understood. Moreover, scientists need to pay more attention to the suitability of candidate species and optimal experimental design. Several authors have commented that studies addressing these issues are clearly warranted (Arnold \& Dewar 2001, Gunn \& Block 2001, Thorsteinsson 2002, Holland \& Braun 2003, Ryder et al. 2006). Given the high cost per PSAT ( US\$3500 to 4200), which has remained relatively stable since their initial development, and the associated deployment costs, experimental designs need to be optimized. Westerberg et al. (1999) concluded that variable reporting rates of electronic tags needed to be incorporated into future sampling designs.

In a few instances, recovered PSATs have allowed identification of specific causes of failure or early detachment. Battery failure (Seitz et al. 2003, Hays et al. 2007, Weng et al. 2007) and antennae damage (Domeier 2006) have been responsible for the former, whereas mechanical failure of the nose cone pin and tethers has been identified as cause of early detachment (Domeier et al. 2003, Stokesbury et al. 2004, Wilson et al. 2005). A variety of other causes have also been hypothesized for early detachment: increased drag as a result of biofouling (Gunn et al. 2003, Kerstetter et al. 2004, Benson \& Dutton 2005, Wilson et al. 2006, Hays et al. 2007); infection and tissue necrosis at the site of the implanted anchoring device (Jellyman \& Tsukamoto 2002, De Metrio et al. 2004, Wilson et al. 2005); entanglement, and social and sexual behaviors of the tagged individuals (Swimmer et al. 2002, 2006, Thorsteinsson 2002). 
Various additional causes of PSAT failure have been hypothesized. These have included expansion and contraction of electronics, batteries, and pressure housings caused by rapid changes in temperature and pressure accompanying extensive vertical movements (Sedberry \& Loefer 2001, Benson \& Dutton 2005, Wilson et al. 2006, Weng et al. 2007); mortality of the tagged individual (Graves et al. 2002, Domeier et al. 2003, Kerstetter et al. 2003, Wilson et al. 2005, Sasso \& Epperly 2007); shark predation (NMFS 1994, Kerstetter et al. 2004, Polovina et al. 2007); and human error (Seitz et al. 2003). Moreover, some batches of PSATs appear to have had higher failure rates (Sasso \& Epperly 2007), implying that problems with specific components or tag assembly were the underlying cause (a similar finding was reported by Gunn \& Block 2001 for archival tags). Lastly, interference on the $401.650 \mathrm{MHz}$ frequency reserved for the Argos satellite system occasionally blocks the $0.5 \mathrm{~W}$ output of the PSATs in at least 2 areas (Mediterranean Sea and near Taiwan) (Howey 2005, Gros et al. 2006, Argos 2007, Gaspar \& Malardé 2007). This interference appears respon- sible for high failure rates of PSATs deployed in the former area (De Metrio et al. 2001, 2002, 2004, 2005).

As for any other tool, it is imperative to know the limitations of PSATs in order to increase performance success of the tags. We therefore investigated PSAT performance by evaluating multiple risk factors and a large sample size of diverse pelagic species. We constructed a 'fault tree' (Fig. 1) to summarize potential risk factors in the pathway PSATs follow from deployment to pop-up (Meeker \& Escobar 1998, Bowers \& Hardy 2006). Specific risk factors associated with tag failure, premature detachment, and the amount of data retrieved were identified to allow an unprecedented appraisal of the overall efficacy of the PSAT technology and to provide a baseline to which future PSAT deployments can be compared.

Our intent was to optimize PSAT performance in future studies by improving our understanding of attachment methodologies, selection of target species, and sampling design. To facilitate future improvements in this technology, a public repository for PSAT

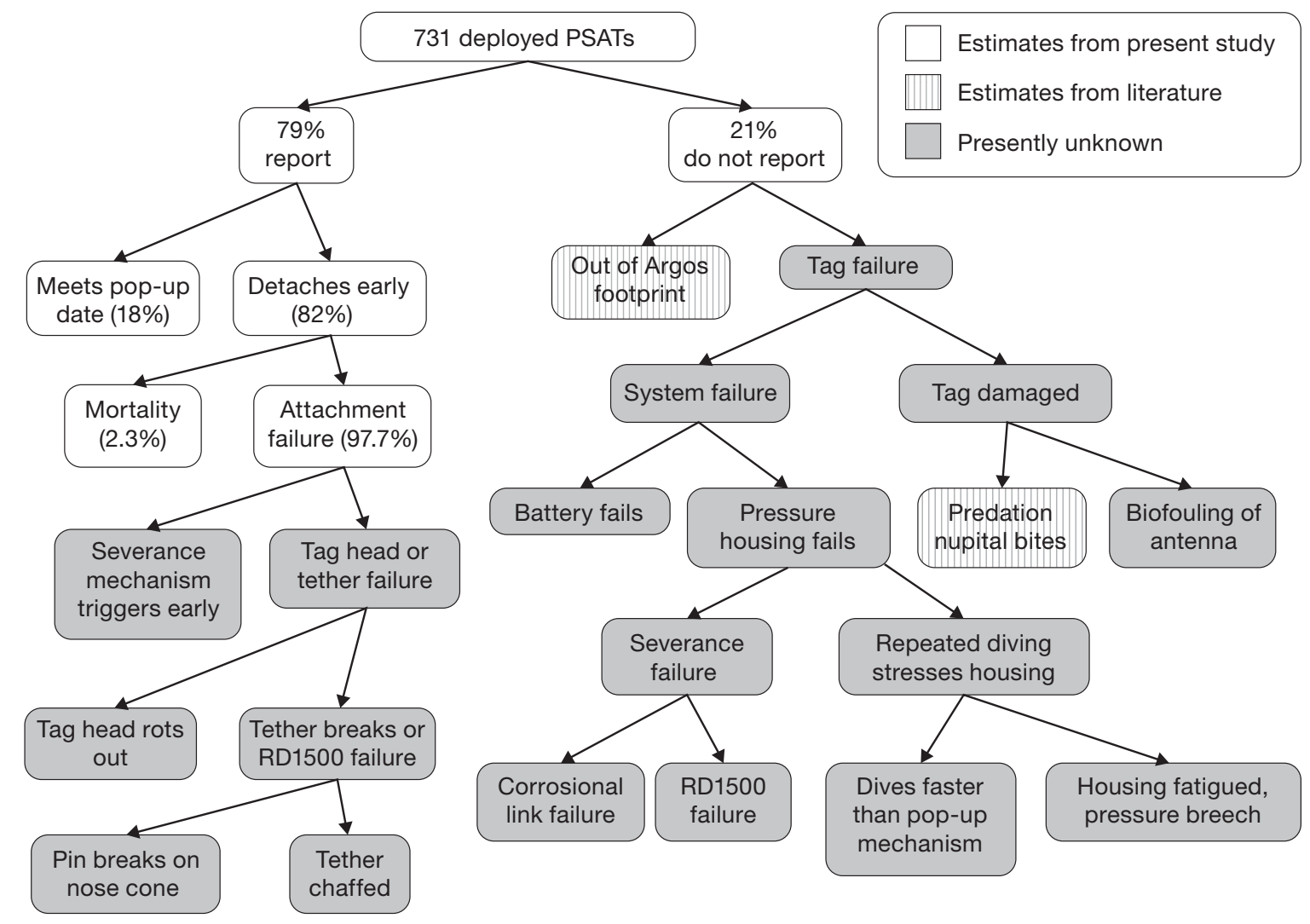

Fig. 1. Fault tree summarizing pop-up satellite archival tag (PSAT) failure modes. Attachment failures are shown on the left and reporting failures are shown on the right. Nodes with stippling represent what has been estimated, white-colored nodes represent what was estimated in the present study and grey is presently unknown. Some nodes could be probably 'pruned' and estimated with accelerated lifetime tests (Meeker \& Escobar 1998). Percentages are conditional on the previous node. For example, on the condition that the PSAT has reported, $82 \%$ of these reported earlier than the planned pop-up date. The mortality estimate (left) comes from data of the Hawaii-based deployments. Out of 214 deployments, 147 reported and of these, 130 reported early and of those, 3 were deemed mortalities. Therefore, early detachment based on mortality is $\sim 2.3 \%$ 
data is in place (www.soest.hawaii.edu/tag-data/) to promote exploration and discovery of PSAT performance and reliability. We encourage researchers to add their data, both successes and failures.

\section{MATERIALS AND METHODS}

Rationale for variable selection. Data on PSAT reporting rates, retention time, and quantity of data transmitted to Argos were collected from 731 PSAT deployments in the Atlantic and Pacific Oceans in the authors' database, which has already been published in part (Swimmer et al. 2002, 2006, Musyl et al. 2004, 2011, Brill et al. 2005, Domeier et al. 2005, Domeier 2006, Moyes et al. 2006, Nielsen et al. 2006, Sibert et al. 2006, Domeier \& Nasby-Lucas 2008). The data represented 19 species, including tunas, billfishes, other teleosts, sharks, and sea turtles (Table 1). All PSATs were equipped with at least one of the 'fail-safe' features described in the 'Introduction' and were assumed to float freely if they detached from the animal prior to the programmed pop-up date (i.e. with tether system still attached). All PSATs were manufactured from 2000 to 2004 and were assumed to be working at the time of deployment regardless of their age.

The following variables were compiled because of their presumed influence on PSAT reporting rates, retention times, and quantity of data transmitted to the Argos system.

(1) Age of PSAT at deployment: days from tag production date to date deployed.

(2) Argos pop-up location: latitude and longitude at which the PSAT began transmitting.

(3) Carapace attachment (only applies to PSATs deployed on turtles): method of PSAT tether connection to the carapace either by holes drilled through the edge (Epperly et al. 2007) or via syntactic foam base-plates attached with epoxy (Swimmer et al. 2002, 2006).

(4) Data acquisition interval ( $I$ ): time interval between data points (for PSATs manufactured by MT), or the time interval at which depth and temperature data were acquired and stored in programmed histogram bins (for PSATs manufactured by WC). During programming of WC PSATs, researchers prioritize which satellite data (geolocation, depth and temperature histograms [HIST], and profiles of depth and temperature [PDTs]) to retrieve first, but this strategy depends on whether the tag remains attached until the pop-up date. If WC PSATs detach before their programmed pop-up date, priority is given to recent HIST and PDT messages (Wildlife Computers 2006). Alternatively, if the programmed pop-up date is reached, geolocation, HIST, and PDT messages are sent with their respective priorities (Wildlife Computers 2006). According to Wildlife
Computers (2006), the expected satellite data return is $\sim 10 \%$ ( 1000 of 10000 transmissions). For more information, see Table S1 in the supplement and the operations manual for WC PSATs covered in this study (www. wildlifecomputers.com/Downloads/Documentation/PAT $4 \% 20$ Manual.pdf). Because of the discrepancy in data products and acquisition strategies, and because the PDTs provided by WC PSATs were not enumerated since 'profiles' often had missing values, the temperature and depth data reported by PSATs are not directly comparable between manufacturers.

(5) Data-days: raw depth and temperature data count or number of geolocations normalized by the data acquisition interval (i.e. the equivalent number of $24 \mathrm{~h}$ periods that the returned data would fill at the specified data acquisition interval without gaps).

(6) Date deployed: date when the PSAT was attached and the animal released.

(7) Depth and habitat class (hereafter referred to as 'habitat class'): species were grouped according to their ecology in the marine environment and extent of vertical movements as either: (a) coastal and estuarine ('coastal'; vertical movements from $\sim 0$ to $50 \mathrm{~m}$, remaining primarily inshore); (b) epipelagic ( $\sim$ to $200 \mathrm{~m}$; mostly confined to surface mixed layer and photic zone with only rare movements beneath the thermocline); (c) mesopelagic I ( 200 to $350 \mathrm{~m}$; occasional movements beneath the thermocline); or (d) mesopelagic II (>350 $\mathrm{m}$; prolonged movements beneath the thermocline) (Hedgpeth 1957, Parin 1970, Whitehead \& Vergara 1978, Musyl et al. 2004, 2011, Bernal et al. 2009). Depth (pressure) has long been suspected of causing PSAT failure, and our impetus for constructing the 4 ordinal habitat classes was to increase the power of statistical inference (Agresti 2002) and to accommodate species that were represented by only one or few PSAT deployments. Habitat class is an ordinal variable coded as $0,1,2$, and 3 to indicate increasing depth.

(8) Number of geolocations: number of daily geolocation estimates retrieved from the PSAT.

(9) Percent pop-up (pctpop): retention time divided by pop-up period. This was used to compare tag retention success.

(10) Pop-up date: calendar date the PSAT detached from the subject.

(11) Pop-up year: calendar year the PSAT detached from the subject.

(12) Pop-up period $(S)$ : number of days from deployment until the programmed pop-up date.

(13) Pop-up season: calendar quarter when the PSAT reported to Argos.

(14) PSAT manufacturer: MT or WC.

(15) Raw data count: number of temperature and depth readings stored in the memory from date of deployment until the PSAT detached from the animal. 


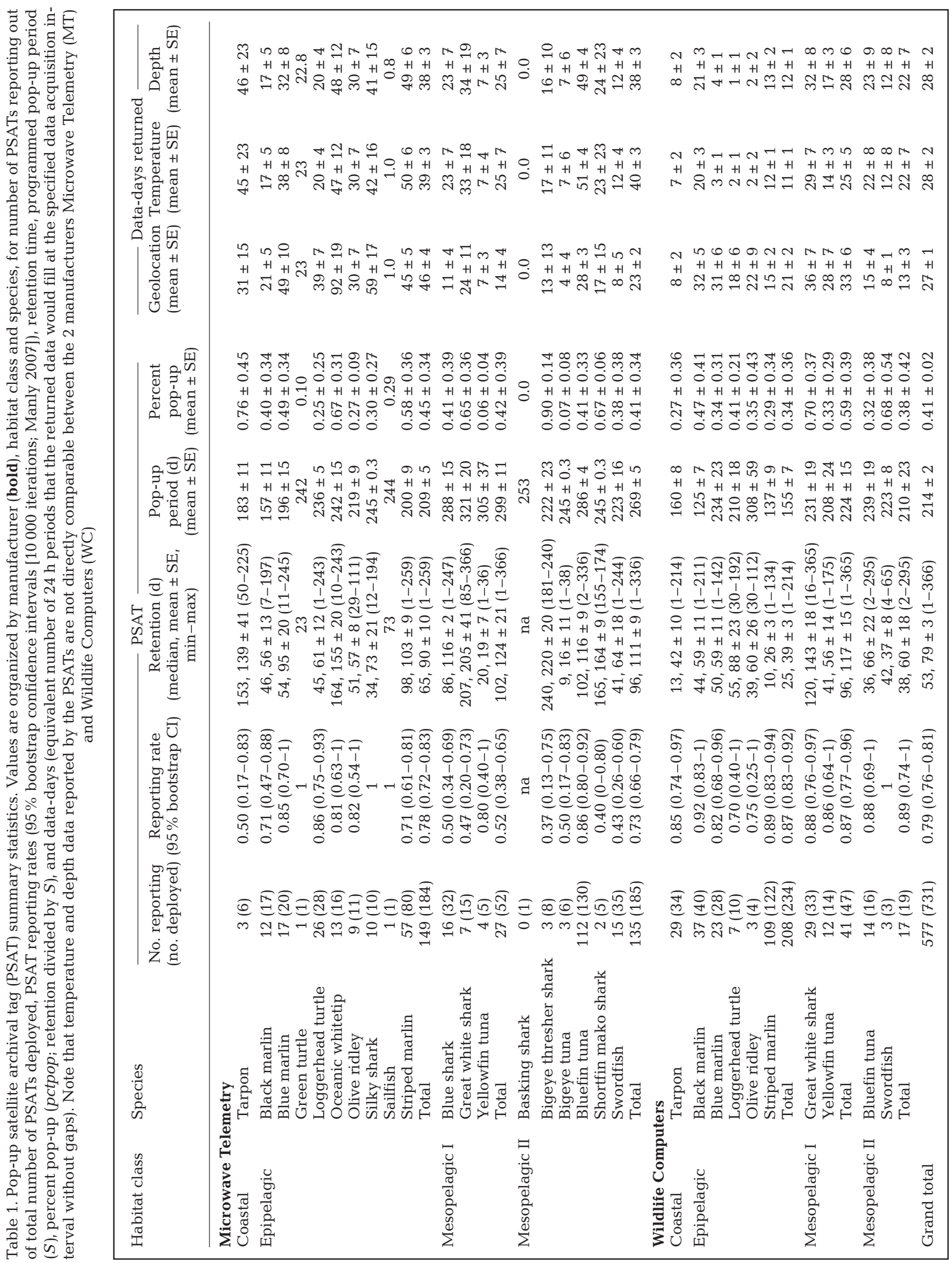


(16) RD1500: Presence or absence of a mechanical detachment device (developed by WC), designed to sever the monofilament tether at $\sim 1500$ to $1800 \mathrm{~m}$ depth. On occasion, this device was paired with MT PSATs.

(17) Region: broad geographic regions used as a proxy for deployment area (the exact deployment locations are proprietary).

(18) Retention time $(t)$ : number of days from PSAT deployment date to the pop-up date (i.e. days-at-liberty). In survival analysis, retention time is a right-censored variable when the PSAT remains attached until the programmed pop-up date.

(19) Set pop-up date: calendar date the PSAT was programmed to detach from the animal.

(20) Species tagged.

(21) Sex: available for some shark species only.

(22) Sunspot activity: sunspot activity interferes with satellite communication (e.g. Ramesh 2000) which is essential to PSAT function. Smoothed monthly sunspot number (Space Weather Prediction Center, www.swpc. noaa.gov/Data/index.html\#indices) was used as a potential explanatory variable to examine PSAT reporting rates.

(23) Swivel: whether or not stainless steel ball-bearing swivels (size no. 6, Sampo Inc.) were incorporated into the tether to reduce rotational forces on the tag head and irregular movements of the PSAT (e.g. precession) (Fredriksson et al. 2007).

(24) Tag production year: based on the calendar date on the invoice (used to indicate the approximate date the batteries were connected to the remainder of the circuitry and subjected to current draw; also a proxy for PSAT year of production or model when this information was unavailable).

(25) Tag serial number: we assumed that PSATs with consecutive serial numbers were manufactured during the same period and from the same component lots.

(26) Tagger: person or research group deploying the PSAT (Domeier, Lutcavage, Musyl, and Swimmer). We used this as an omnibus variable to account for e.g. differences in tagging method, platform (e.g. type of boat), and handling procedures. The majority of PSATs were deployed by the authors themselves. For sea turtles, however, 54 PSATs were deployed by 28 individuals. As a result, we could not examine the effect of individual tagger on tag performance. For marlin in Hawaii, 46 PSATs were deployed by 16 individuals. In this case deployments by individual sports fishing boats were pooled.

(27) Tagging method: whether the PSAT was attached while the subject remained in the water or after it was brought aboard and restrained on deck.

(28) Tag heads: tag heads were either surgical grade nylon (Block et al. 1998, Lutcavage et al. 1999, Prince et al. 2002), titanium (Block et al. 1998), stainless steel
(Wilson et al. 2005), nylon 'umbrella' design (Domeier et al. 2003), or surgical grade nylon darts augmented with opposable stainless steel spear gun flopper blades (small barbs, H-3010, Riffe International) to increase surface area, similar to the design of Watkins (1979). PSATs were also attached to some sharks using a harness made of Tygon tubing and braided stainless steel passed through the dorsal fin (Moyes et al. 2006).

(29) Tether material: the main tether types were monofilament, monofilament with silicone tubing, fluorocarbon, fluorocarbon with braided stainless steel wire (used for PSAT attachment to some turtles and in shark harnesses), or braided stainless steel wire only. Crimps used to construct tethers were stainless steel. Brass crimps like the ones used in Jellyman \& Tsukamoto (2002) promote electrolysis, which could interfere with the PSAT's detachment mechanism.

Imputation of missing data. For missing data, we assumed data were missing at random and applied a single variable imputation method which involved randomly selecting a valid value to substitute for the missing data (Meng 2000, Donders et al. 2006).

Model selection. Model selection proceeded using Akaike's Information Criteria (AIC, Agresti 2002). All potential explanatory variables (including first order interactions) were evaluated by stepwise selection (Agresti 2002) using a statistical significance level of $\alpha=0.05$. Model fit was examined using standardized residuals and goodness-of-fit statistics (Hosmer \& Lemeshow 1989); in the case of logistic regression, concordance was calculated (Agresti 2002).

PSAT reporting rates. Logistic regression (generalized linear model, Agresti 2002) was used to analyze the proportion of PSATs which successfully transmitted to Argos. The logit is the link function relating the linear combination of the explanatory variables $(X)$ to the proportion of PSATs that successfully report to $\operatorname{Argos}(\pi)$ :

$$
\log _{\mathrm{e}}\left(\frac{\pi}{1-\pi}\right)=\alpha+\beta X
$$

where $\alpha$ is the intercept and $\beta$ is the slope. Model fitting was conducted with Proc LOGISTIC in SAS 9.1.3 by maximizing the log likelihood (Agresti 2002, Myers et al. 2002). Odds ratios (ORs) can be obtained from the fitted coefficients $(\hat{\beta})$ for the explanatory variables by the inverse link (exponential) function. The OR is a multiplicative effect, either increasing (OR $>1)$ or decreasing $(\mathrm{OR}<1)$ the odds that the PSAT will report.

Retention time. Retention time $(t)$ was considered dependent on the following set of variables: Argos popup location, habitat class, pop-up period, PSAT manufacturer, region, species tagged, swivel, tagger, tag head, and tether material. Retention times were summarized with Kaplan-Meier survival curves (Allison 1995). Only reporting tags were analyzed for retention 
time with Cox proportional hazards $(\mathrm{CPH})$ models because time-to-event data are required (Cox 1972, Allison 1995). If a PSAT fails to report then retention time is unknown. Retention time is a censored variable as the PSAT may well have remained attached much longer than its programmed pop-up date. $\mathrm{CPH}$ models correctly handle censored variables while assessing risk factors for early detachment (Allison 1995, Meeker \& Escobar 1998).

Three separate data sets were analyzed for retention time: (1) teleost and shark deployments with PSATs affixed with tag heads $(\mathrm{n}=491)$, (2) PSATs attached to sharks using a harness $(\mathrm{n}=40)$ or a tag head $(\mathrm{n}=40)$, and (3) all sea turtles $(n=46)$. Retention time was assumed to be independent of reporting success, which implied that failed tags have similar (albeit unobservable) retention outcomes.

The risk of early detachment is described by the hazard function:

$$
h(t)=\exp \left(\beta_{1} X_{1}+\beta_{2} X_{2}+\beta_{3} X_{3}+\ldots+\beta_{\mathrm{p}} X_{\mathrm{p}}\right) h_{0}(t)
$$

where $h(t)$ is the hazard function (i.e. risk of tag detachment at retention time $t), X_{1}, X_{2}, X_{3}, \ldots X_{\mathrm{p}}$ are the explanatory variables in the model, and $\beta_{1}, \beta_{2}, \beta_{3}, \ldots \beta_{\mathrm{p}}$ are the coefficients that describe the contribution of these variables. $h_{0}(t)$ is the baseline hazard function at retention time $t$ (i.e. the risk of tag detachment if all explanatory variables are equal to zero or to a defined base value). The hazard function is a measure of risk of early detachment as a function of retention time. Inferences are made by considering the hazard ratio (HR), which is obtained by evaluating the hazard function given in Eq. (2) at 2 levels of the independent variable $X_{\mathrm{p}}$. For example, the HR comparing 2 habitat classes is the ratio of the hazard function evaluated at those 2 levels. For continuous variables like latitude and longitude, the HR is defined as the change in hazards associated with a $1^{\circ}$ change. Since the baseline hazard function appears in both the numerator and denominator of the HR, the factor cancels out and thus does not need to be estimated (Allison 1995).

If $\mathrm{HR}>1$, then the factor is considered more risky to retention time; if the $\mathrm{HR}$ is $<1$, then the factor is considered less risky to retention time. The proportional hazards assumption is that the risks associated with a given variable are approximately constant over time. This assumption was tested by checking scaled Schoenfeld residuals for any discernible pattern (Allison 1995). Models were fitted with Proc LIFETEST and Proc PHREG in SAS 9.1.3.

PSAT data return. The number of geolocations and the raw data count for depth and temperature were normalized by data acquisition interval $(I)$ to derive a variable called data-days $\left(n^{\prime}\right)$ scaled in a common unit (d) for all 3 data types:

$$
\begin{gathered}
n_{\mathrm{D}}^{\prime}=\mathrm{n}_{\mathrm{D}} /(24 / I) \\
n_{\mathrm{T}}^{\prime}=\mathrm{n}_{\mathrm{T}} /(24 / I) \\
n_{\mathrm{L}}^{\prime}=\mathrm{n}_{\mathrm{L}}
\end{gathered}
$$

where $\mathrm{n}$ is the raw data count, and the subscripts $\mathrm{D}, \mathrm{T}$, and $\mathrm{L}$ are depth, temperature, and geolocation, respectively. Data-days were used to analyze data return versus pop-up period after normalizing for different data acquisition intervals. If the PSAT failed to report, then data-days was zero.

Data density $(\delta)$ is designed to address issues related to data acquisition interval and is independent of popup period:

$$
\delta=\left[\mathrm{n}_{\mathrm{D}}+\mathrm{n}_{\mathrm{T}}+\mathrm{n}_{\mathrm{L}} / 3\right] / t
$$

where $t$ is the retention time in days. The numerator represents the average data points of all 3 types. Data density is thus the average number of data points of each type per day of deployment.

Missing data. Data points can be lost if the PSAT detaches from the animal prior to the programmed pop-up date, which truncates the time series. Data can also be lost if data were not successfully written to the PSAT's memory or were not transmitted to Argos. The proportion of missing data $\left(M_{r}\right)$ as a result of shed tags was estimated as:

$$
M_{r}=1-t / S
$$

where $S$ is the pop-up period. The proportion of data missing because of Argos transmission problems and data recording issues $\left(M_{\mathrm{A}}\right)$ was estimated as:

$$
M_{\mathrm{A}}=1-\left(\mathrm{n}_{\mathrm{D}}+\mathrm{n}_{\mathrm{T}}+\mathrm{n}_{\mathrm{L}}\right) /(2 \times 24 t / I+t)
$$

The maximum number of points returned by a PSAT is given by the denominator in Eq. (6). Temperature and depth data were scaled by data acquisition interval $(I)$, in exactly the same way (hence the 2 in the denominator). There can be, at most, 1 high quality geolocation point per day regardless of the data acquisition interval.

PSAT data return model. A non-parametric, empirical cumulative distribution function (ECDF) was used to examine data return rates and is an unbiased consistent estimator of the cumulative probability distribution function (Rice 1995). PSATs that failed to report returned no data-days and are represented by the vertical intercept of an ECDF.

The expected value of data-days was considered analogous to the Ricker type of spawner-recruit model (Quinn \& Deriso 1999):

$$
n^{\prime}=\left(a S \mathrm{e}^{b S+\beta X}\right) \varepsilon
$$

where $X$ represents explanatory variables (age of PSAT at deployment, tag production year, and habitat 
class), $\beta$ describes the contribution of these variables in the models and $\varepsilon$ is an error term. Parameter $a$ is the intercept and parameter $b$ is the decay rate which describes the effects of the pop-up period and is necessary for testing the existence of an optimal pop-up period. The variance increased as predicted values of $n^{\prime}$ increased so a multiplicative error structure was assumed in Eq. (7). Models were fitted using nonlinear least squares (Jennrich 1994) implemented in Proc NLIN in SAS 9.1.3 as:

$$
\log \left(n^{\prime}+1\right)=\log (a)+\log (S)+b S+\beta X
$$

We assumed that there is an instantaneous probability of PSAT failure at the time of tag attachment and that this probability accumulates throughout the lifetime of the deployment. The decline in expected data return can be compared to the concept of density dependence and can be tested in a similar way. For example, a good fit of the strictly increasing BevertonHolt model implies a lack of an optimal pop-up period $\left(S^{*}\right)$ (Quinn \& Deriso 1999). The existence of an optimal pop-up period is tested with a likelihood ratio test comparing the likelihood of an alternative model to the likelihood of the Beverton-Holt model. The null hypothesis is that $b=0$, which implies there is no $S^{*}$ and that $n$ increases monotonically regardless of the popup period (Jennrich 1994). If $b$ is found to be significantly different from zero, then $S^{*}$ exists (Quinn \& Deriso 1999). $S^{*}$ was derived from Eq. (8) by solving the equation $\mathrm{d} n^{\prime} / \mathrm{d} S=0$, which yielded:

$$
S^{*}=-1 / b
$$

Confidence intervals for this estimator were obtained by bootstrapping (10000 iterations) the residuals of the given model (Manly 2007).

Meta-analysis of PSAT performance. PSAT reporting rates from the published literature were analyzed using resampling methods (Adams et al. 1997, Gurevitch \& Hedges 1999, Manly 2007) assuming heterogeneity (i.e. random-effects model, where each study was assumed to have its own reporting rate and variance). The percentiles of the bootstrap sampling distributions were then used to summarize the reporting rates by species, habitat class, and PSAT manufacturer. Some studies appear to have described only PSATs that reported, therefore introducing bias into the analysis. Sometimes 2 or more articles describing different aspects of the same PSAT deployments were found. In these cases, we took care to only include the results of these deployments once. Other articles described results from multiple years or multiple types of deployments which we refer to as 'studies'. Using these selection criteria, 81 PSAT studies in 53 peer-reviewed articles reporting the deployment of 1433 PSATs (1052 WC PSATs and 379 MT PSATs) on 23 marine species were found (see Table S2 in the supplement at www. int-res.com/articles/suppl/m433p001_supp.pdf). A funnel plot with sample size versus PSAT reporting rate was used as a diagnostic test for publication bias (Gurevitch \& Hedges 1999), but study sizes were often small (i.e. $25 \%$ of the studies described 1 or 2 PSAT deployments, and $50 \%$ described 6 or fewer deployments).

PSAT performance comparison. Log likelihood ratio tests (Agresti 2002) were used to compare reporting rates from the authors' database and literature review by fitting a succession of nested logistic regression models and comparing the likelihoods of the 2 nested models. Using log likelihood ratio tests, PSAT reporting rates by habitat class and by manufacturer between the data sources were also compared. For those species common to both the literature review and the authors' database, the Wald test statistic (Zar 1996), or for smaller samples, a nonparametric permutation test with 3000 iterations (Manly 2007), was used to test for differences in PSAT reporting rates.

\section{RESULTS}

The authors' database included 731 PSATs and 19 species. PSATs transmitted data to the Argos satellite system over latitudes from $\sim 45^{\circ} \mathrm{N}$ to $60^{\circ} \mathrm{S}$ (Fig. 2). Performance metrics segregated by species are summarized in Table 1. The overall PSAT reporting rate was $79 \%$, and separated by manufacturer the reporting rate was $73 \%$ (311 of 427 ) for MT and $86 \%$ (266 of 304) for WC. Retention time ranged from 1 to $366 \mathrm{~d}$ (median $=53 \mathrm{~d}$, mean $\pm \mathrm{SE}=79 \pm 3 \mathrm{~d}$ ) and programmed pop-up periods ranged from 8 to $395 \mathrm{~d}$ (median $=242 \mathrm{~d}$, mean $=214 \pm 3 \mathrm{~d}$ ). Of the 577 PSATs that reported, only $18 \%$ (106) remained attached until the programmed pop-up period (mean pop-up period $=155 \pm 9 \mathrm{~d}$ ), while $82 \%$ (471) detached early (mean pop-up period $=224 \pm$ $3 \mathrm{~d})$. Overall, PSATs remained attached for $41 \%$ of the programmed pop-up period (mean pctpop $=0.41 \pm$ 0.01). By manufacturer, pctpop was $0.44 \pm 0.02$ and $0.38 \pm 0.02$ for MT and WC PSATs, respectively.

\section{PSAT reporting rates}

Logistic regression models for reporting rates of PSAT deployments are presented in Table 2 (Table S3 in the supplement provides full model output). The best-fitting model was $67 \%$ concordant with the observed data and showed no significant lack of fit $\left(\chi^{2}=6.27, d f=7, p=0.5\right)$. This model included the variables for pop-up year, habitat class, tagger, and manufacturer, as well as a significant interaction between manufacturer and habitat class (Table 2). The second 


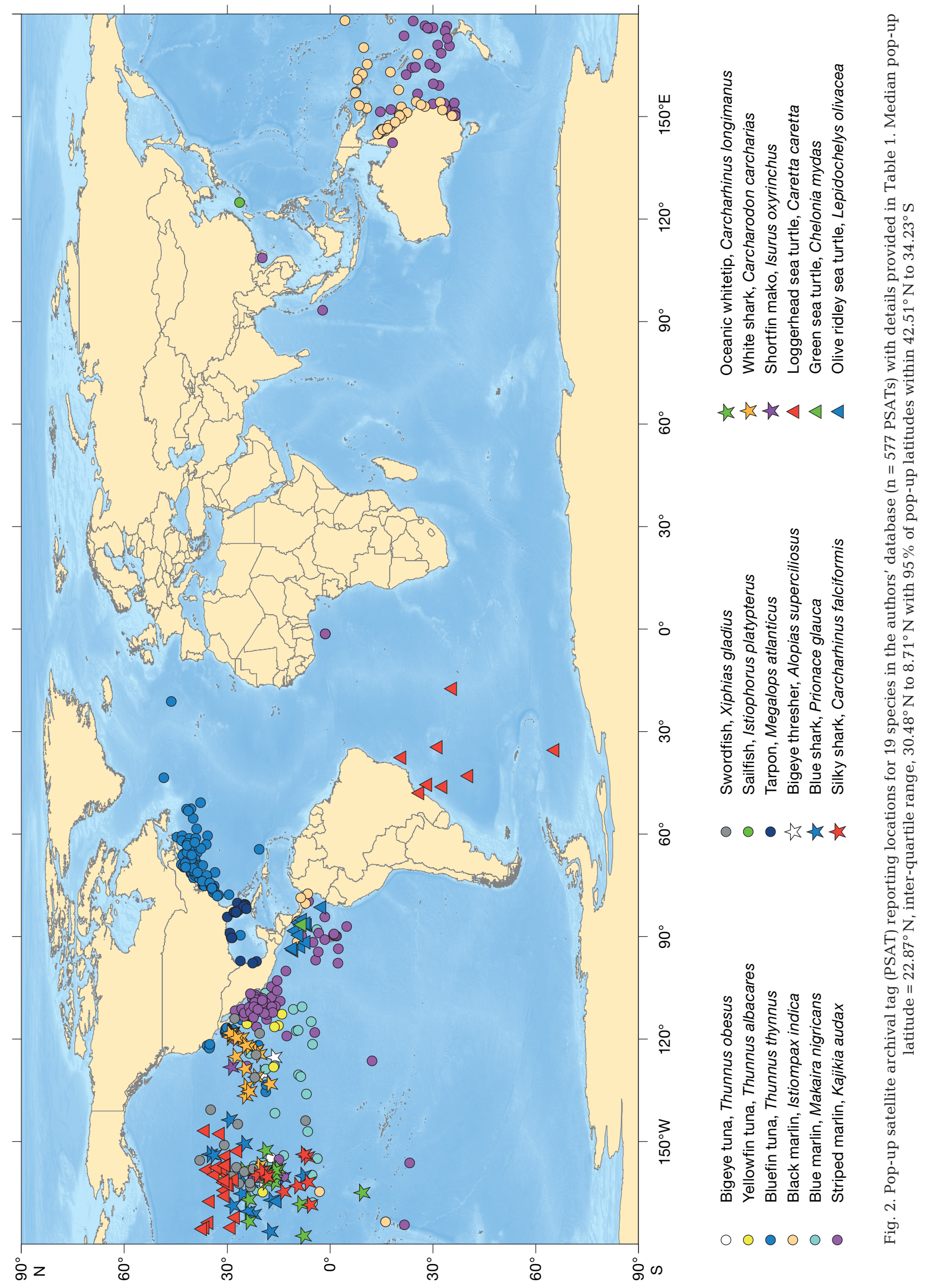


Table 2. Pop-up satellite archival tag (PSAT) reporting rates modeled with logistic regression. The p-values are from log likelihood ratio tests with and without the given variable. In the best fitting model (i.e. AIC with lowest value) there is a habitat class and PSAT manufacturer interaction, which implies that there is a different odds ratio at each habitat class for each PSAT manufacturer $(\mathrm{MT}=$ Microwave Telemetry, $\mathrm{WC}=$ Wildlife Computers). Detailed descriptions for variables can be found in 'Materials and methods - rationale for variable selection'

\begin{tabular}{|c|c|c|c|}
\hline Model & AIC & Odds ratio & $\mathrm{p}$ \\
\hline $\begin{array}{l}\text { Reporting rate } \approx \text { Tagger }+ \\
\text { Habitat class }+ \text { PSAT manufacturer }+ \\
\text { Habitat class } \times \text { PSAT manufacturer }+ \\
\text { Pop-up year }\end{array}$ & 696.0 & $\begin{array}{l}\text { 0.678 Domeier vs. Swimmer } \\
\text { 4.606 Lutcavage vs. Swimmer } \\
\text { 0.700 Musyl vs. Swimmer } \\
\text { 0.890 MT vs. WC (Coastal) } \\
\text { 0.596 MT vs. WC (Epipelagic) } \\
\text { 0.400 MT vs. WC (Mesopelagic I) } \\
\text { 0.268 MT vs. WC (Mesopelagic II) } \\
\text { 1.216 per Pop-up year }\end{array}$ & $\begin{array}{l}0.251 \text { (Habitat class) } \\
0.610 \text { (PSAT manufacturer) } \\
0.011 \text { (Habitat class } \times \text { PSAT manufacturer) } \\
0.019 \text { (Pop-up year) }\end{array}$ \\
\hline $\begin{array}{l}\text { Reporting rate } \approx \text { PSAT manufacturer }+ \\
\text { Pop-up year }\end{array}$ & 717.7 & $\begin{array}{l}0.293 \text { MT vs. WC } \\
1.361 \text { per Pop-up year }\end{array}$ & $\begin{array}{l}<0.0001 \text { (PSAT manufacturer) } \\
<0.0001 \text { (Pop-up year) }\end{array}$ \\
\hline $\begin{array}{l}\text { Reporting rate } \approx \text { PSAT manufacturer }+ \\
\text { Tag production year }{ }^{\mathrm{a}}\end{array}$ & 723.1 & $\begin{array}{l}0.316 \text { MT vs. WC } \\
1.314 \text { per Production year }\end{array}$ & $\begin{array}{r}<0.001 \text { (PSAT manufacturer) } \\
0.003 \text { (Tag production year) }\end{array}$ \\
\hline
\end{tabular}

best model included the variables for pop-up year and PSAT manufacturer, and indicated that the odds of a PSAT successfully reporting have significantly increased over time (Fig. 3).

\section{PSAT retention times}

Teleosts and sharks: tag heads

Of 491 PSATs affixed to teleosts and sharks using tag heads and tethers, $80 \%$ detached before the programmed pop-up date. Summaries of retention times

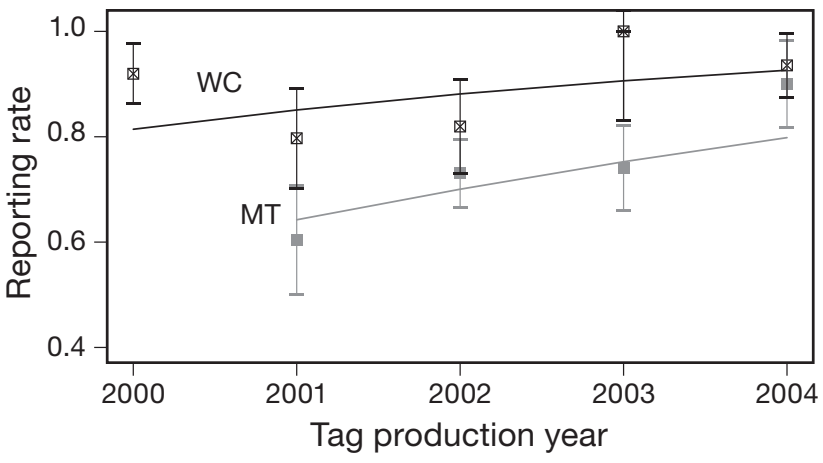

Fig. 3. Observed (markers) and model-predicted (curves) pop-up satellite archival tag (PSAT) reporting rates by tag production year. This is a model of the form: Reporting rate $\approx$ Manufacturer + Tag production year, which summarizes across tagger and habitat classes (see Table 2). WC = Wildlife Computers $(\mathrm{n}=304)$ and MT $=$ Microwave Telemetry $(\mathrm{n}=427)$. The error bars represent $95 \%$ confidence intervals of the observed reporting rates are provided in Table 1. Kaplan-Meier survival curves based on species (Fig. 4A) demonstrated that PSATs deployed on great white sharks had the longest retention times, followed by those deployed on bluefin tuna. The retention times of the remaining species were tightly bunched. Survival curves based on habitat class (Fig. 4B) showed 2 groupings, coastal and epipelagic versus mesopelagic I and II, with the mesopelagic group exhibiting significantly higher retention times. Survival curves comparing PSAT manufacturer indicated that WC tags showed significantly less retention success ( $p<0.0001$ ) than MT tags (Fig. 4C). Retention by tag head indicated that nylon tag heads had significantly shorter retention times $(p<0.0001)$ than all other types (Fig. 4D).

$\mathrm{CPH}$ retention models are summarized in Table 3 (Table S4 in the supplement provides full model output). The best-fitting model (AIC $=4120.5$ ) exhibited significant interaction between habitat class and Argos pop-up latitude. Less than $5 \%$ of the absolute standardized residuals exceeded 2 for this model. Increasing both habitat class ( $\mathrm{HR}=0.311$ per habitat class) and Argos pop-up latitude ( $\mathrm{HR}=0.986$ per degree) significantly reduced the risk of early detachment. An increase of $10^{\circ}$ latitude reduced the hazard of early detachment by a multiplicative factor of $0.986^{10}=0.886$. This trend was evident over the entire range of pop-up latitudes with significant positive correlation between retention time and Argos pop-up latitude (Fig. S1 in the supplement at www.int-res.com/articles/suppl/ m433p001_supp.pdf). The preferred model also exhibited significant effects attributable to tag head, tether 

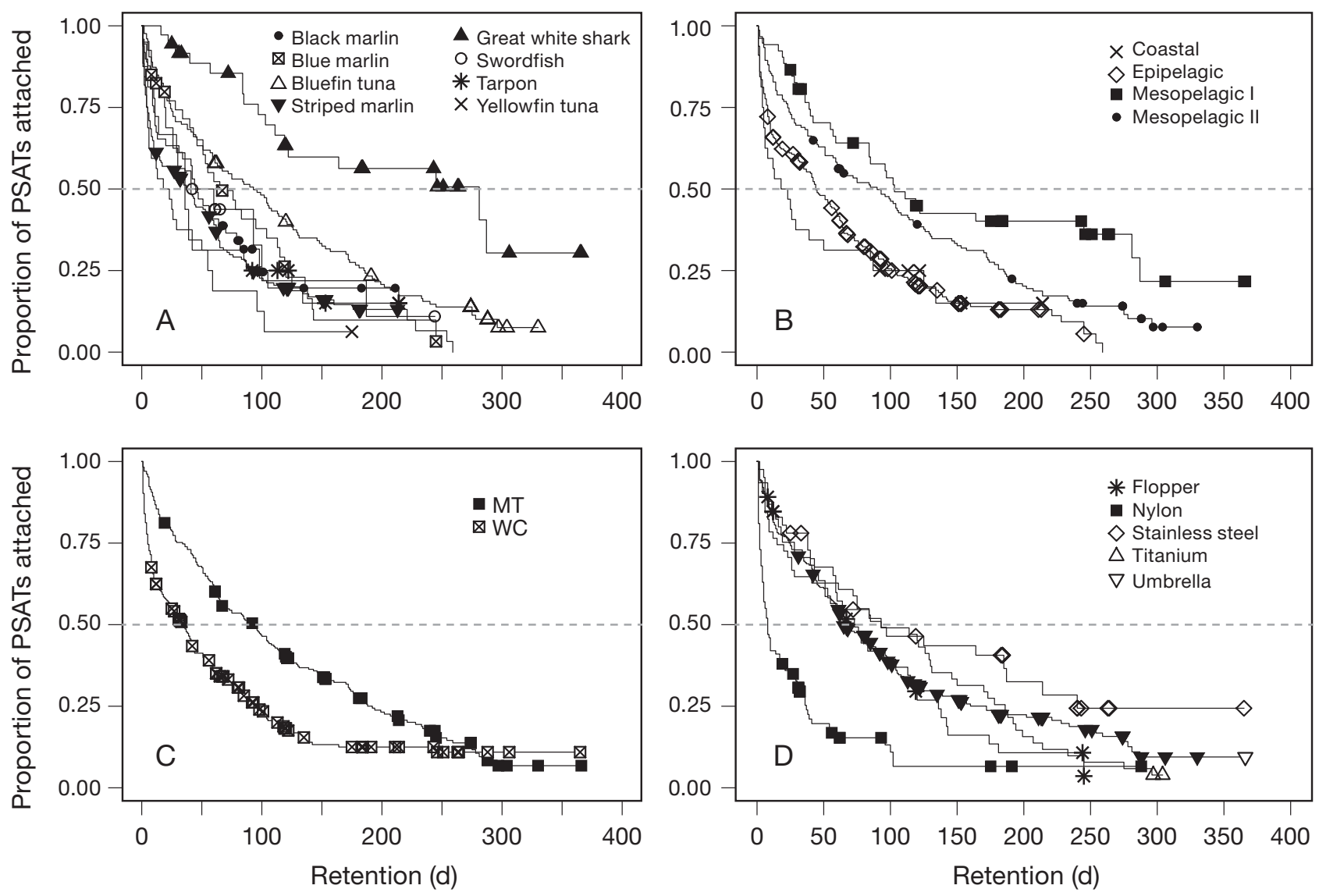

Fig. 4. Kaplan-Meier (KM) survival curves of the proportion of pop-up satellite archival tag (PSATs) remaining attached. A step downward on the survival curve represents a PSAT which detached early, while a symbol (legend) is a PSAT that hit its programmed pop-up date. The median is found at the intersection of the lightly dashed 50th percentile line and the survival curve. (A) KM survival curves for teleosts and sharks when PSATs were affixed by tag head indicated significant differences between species (log likelihood ratio test, LLRT; $\chi^{2}=95.3, \mathrm{df}=7, \mathrm{p}<0.0001$ ). (B) KM survival curves for teleosts and sharks were significantly different (LLRT, $\chi^{2}=53.6, \mathrm{df}=3, \mathrm{p}<0.0001$ ) by habitat class. (C) KM survival curves for teleosts and sharks indicated significant differences (LLRT, $\chi^{2}=46.3, \mathrm{df}=1, \mathrm{p}<0.0001$ ) by manufacturer (WC $=$ Wildlife Computers and MT $=$ Microwave Telemetry). (D) KM survival curves for teleosts and sharks were significantly different (LLRT, $\chi^{2}=96.6, \mathrm{df}=4, \mathrm{p}<0.0001$ ) by tag head

material, pop-up season, RD1500, PSAT manufacturer, and tag production year. PSAT retention was significantly better with the absence of an RD1500 and MT PSATs had significantly better retention than WC PSATs. The PSATs programmed to pop-up during the third quarter (July, August and September) had significantly poorer retention compared to other quarters. Retention time was not significantly different (ANOVA, $\mathrm{p}=0.5$ ) for austral samples by quarter $(\mathrm{n}=88$, all epipelagic species). Therefore, these samples did not have a strong impact on the model.

\section{Sharks}

Of all the PSATs attached to sharks (including those attached by harness and tag head), 80 tags reported and $65 \%$ detached before the programmed pop-up date. Summaries of retention times are provided in Table 1. Kaplan-Meier survival curves for sharks indicated significant differences in retention times (Fig. 5A). Immobilizing animals on deck was associated with significantly shorter $(p=0.002)$ retention (Fig. 5B), but survival curves for PSAT retention by habitat class were not significantly different $(p=0.176)$ (Fig. 5C). The best-fitting $\mathrm{CPH}$ retention model for sharks retained only tagging method (Table S5 in the supplement gives full output). No multivariate model was found that fit the data significantly better, and several univariate models were equivalent (tagging method and tag head) as identified by AICs within \pm 2 units. Less than $5 \%$ of the absolute standardized residuals were $>2$ for the best-fitting model, and attaching the PSAT with the shark on deck versus in the water had a HR of 2.6. The CPH tag head model showed that harnesses have a HR over twice that for nylon umbrella 
Table 3. Pop-up satellite archival tag (PSAT) retention modeled with Cox proportional hazards. Retention and hazard ratios quantify the change in risk compared to a baseline category. The p-values are from log likelihood ratio tests with and without a given variable. $\mathrm{n}=491$ tagged animals, including 40 sharks with PSATs affixed using tag heads. Lower values of AIC imply a better fitting model. PSAT manufacturers: MT = Microwave Telemetry, WC $=$ Wildlife Computers. Detailed descriptions for variables can be found in 'Materials and methods - Rationale for variable selection'

\begin{tabular}{|c|c|c|c|}
\hline Model & AIC & Hazard ratio & $\mathrm{p}$ \\
\hline $\begin{array}{l}\text { Retention } \approx \text { Tag head }+ \\
\text { Tether + Pop-up season }+ \\
\text { Tag production year }+ \\
\text { RD1500 + Manufacturer }+ \\
\text { Habitat class + ILatitudel + } \\
\text { Habitat class } \times \text { ILatitudel }\end{array}$ & 4120.5 & $\begin{array}{l}\text { 0.827 Flopper vs. Umbrella } \\
\text { 8.480 Nylon vs. Umbrella } \\
\text { 1.397 Stainless steel vs. Umbrella } \\
\text { 1.806 Titanium vs. Umbrella } \\
\text { 5.964 Fluorocarbon vs. Stainless steel } \\
\text { 2.709 Monofilament vs. Stainless steel } \\
\text { 3.173 Monofilament + Silicone } \\
\quad \text { tubing vs. Stainless steel } \\
\text { 0.947 1st quarter vs. 4th quarter } \\
\text { 0.901 2nd quarter vs. 4th quarter } \\
\text { 1.378 3rd quarter vs. 4th quarter } \\
\text { 1.215 per Tag production year } \\
\text { 1.516 RD1500 ‘No' vs. 'Yes' } \\
\text { 0.459 MT vs. WC } \\
\text { 0.311 per Habitat class } \\
\text { 0.986 per degree of ILatitudel } \\
\text { HR }^{b} \text { Habitat class } \times \text { ILatitudel }\end{array}$ & $\begin{array}{l}0.028 \text { (Pop-up season) } \\
0.025 \text { (Tag production year) } \\
0.020 \text { (RD1500) } \\
<0.0001 \text { (Manufacturer) } \\
<0.0001 \text { (Habitat class) } \\
0.342 \text { (ILatitudel) } \\
<0.001 \text { (Habitat class } \times \text { ILatitudel) }\end{array}$ \\
\hline $\begin{array}{l}\text { Retention } \approx \text { Tag head }+ \\
\text { Tagger }+ \text { Pop-up season }+ \\
\text { Habitat class }+ \text { Manufacturer }+ \\
\text { RD1500 }\end{array}$ & $\begin{array}{r}4138.2 \\
+\end{array}$ & $\begin{array}{l}\text { 0.454 Flopper vs. Umbrella } \\
\text { 3.744 Nylon vs. Umbrella } \\
\text { 0.888 Stainless steel vs. Umbrella } \\
\text { 1.490 Titanium vs. Umbrella } \\
\text { 0.314 Domeier vs. Musyl } \\
\text { 0.782 Lutcavage vs. Musyl } \\
\text { 0.844 1st quarter vs. } 4 \text { th quarter } \\
\text { 0.859 2nd quarter vs. } 4 \text { th quarter } \\
\text { 1.456 3rd quarter vs. } 4 \text { th quarter } \\
\text { 0.635 per Habitat class } \\
\text { 0.452 MT vs. WC } \\
\text { 1.661 RD1500 'No' vs. 'Yes' }\end{array}$ & $\begin{array}{l}\left.\ll 0.0001 \text { (Tag head }^{\mathrm{a}}\right) \\
<0.001 \text { (Tagger) } \\
<0.001 \text { (Pop-up season) } \\
<0.001 \text { (Habitat class) } \\
<0.001 \text { (Manufacturer) } \\
0.004 \text { (RD1500) }\end{array}$ \\
\hline $\begin{array}{l}\text { Retention } \approx \text { Tag head }+ \\
\text { Habitat class + ILatitudel }\end{array}$ & 4173.8 & $\begin{array}{l}\text { 1.337 Flopper vs. Umbrella } \\
\text { 3.489 Nylon vs. Umbrella } \\
\text { 0.953 Stainless steel vs. Umbrella } \\
\text { 1.398 Titanium vs. Umbrella } \\
\text { 0.672 per Habitat class } \\
\text { 1.020 per degree of ILatitudel }\end{array}$ & $\ll 0.0001\left(\right.$ Tag head $\left.^{\mathrm{a}}\right)$ \\
\hline
\end{tabular}

tag heads. Within this model, only the HR of harness and nylon tag heads was significantly different $(\mathrm{p}=$ 0.006) from 1 (no effect).

\section{Sea turtles}

PSATs were attached to 3 species of sea turtles $(\mathrm{n}=$ 54, Table 1). Only one PSAT had its tether attached to holes drilled in the carapace; the remaining PSATs were attached using foam base-plates glued to the carapace with epoxy. Kaplan-Meier survival curves among turtle species examining PSAT retention times were not significantly different (log likelihood ratio test, $\chi^{2}=1.06, p=0.6$ ) and, thus, data were pooled to compare retention time to non-turtle species (Fig. 6A). As a group, sea turtles had significantly poorer PSAT retention when compared to teleosts and sharks. PSATs deployed on turtles tend to remain attached for the initial 6 wk period post-release, but afterwards attachments failed rapidly. Less than $25 \%$ of turtle PSATs were retained after $70 \mathrm{~d}$ as compared to the 25th percentile of $150 \mathrm{~d}$ for teleosts and sharks. Only one PSAT deployed on a sea turtle reached the pro- 

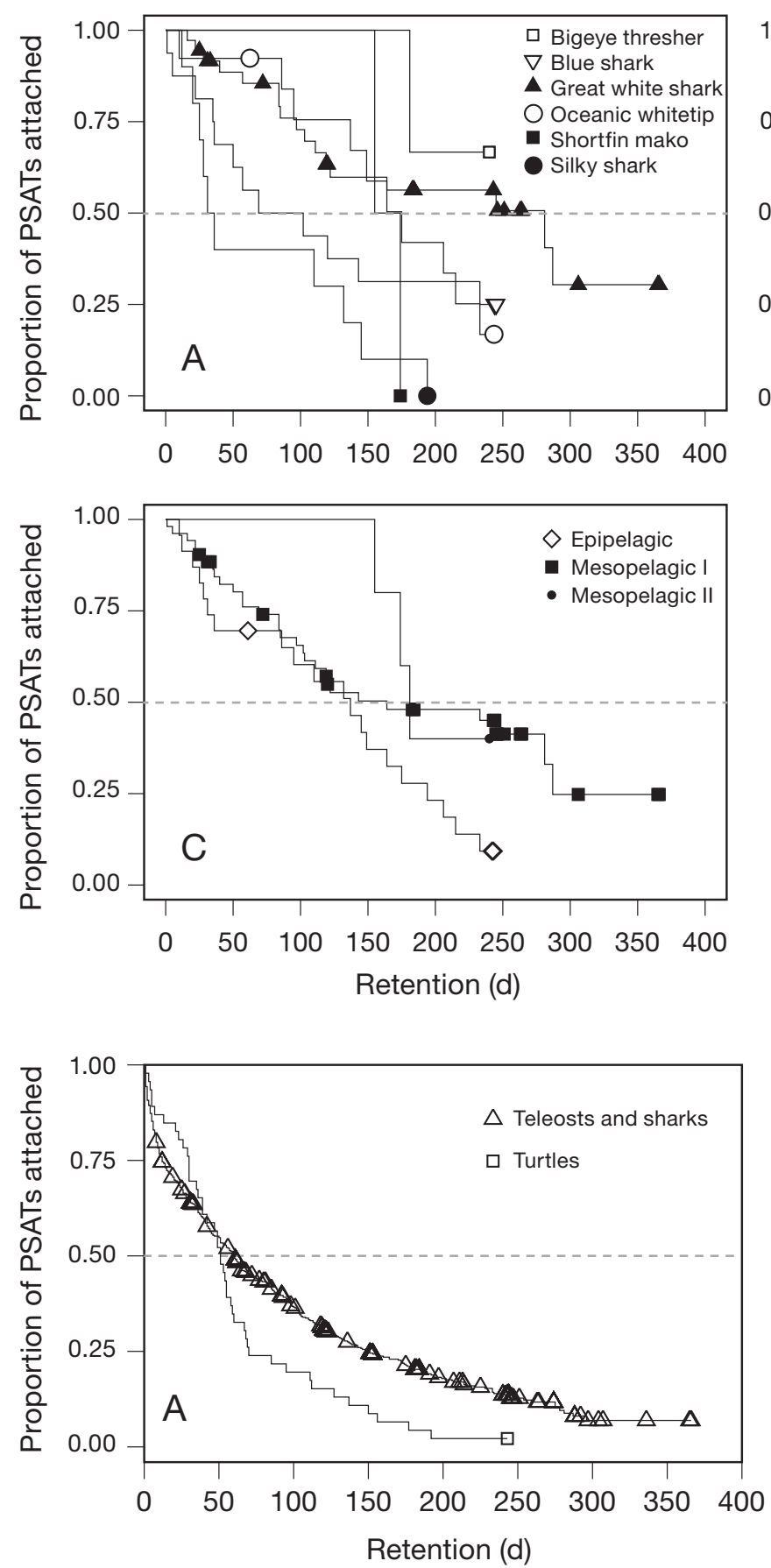

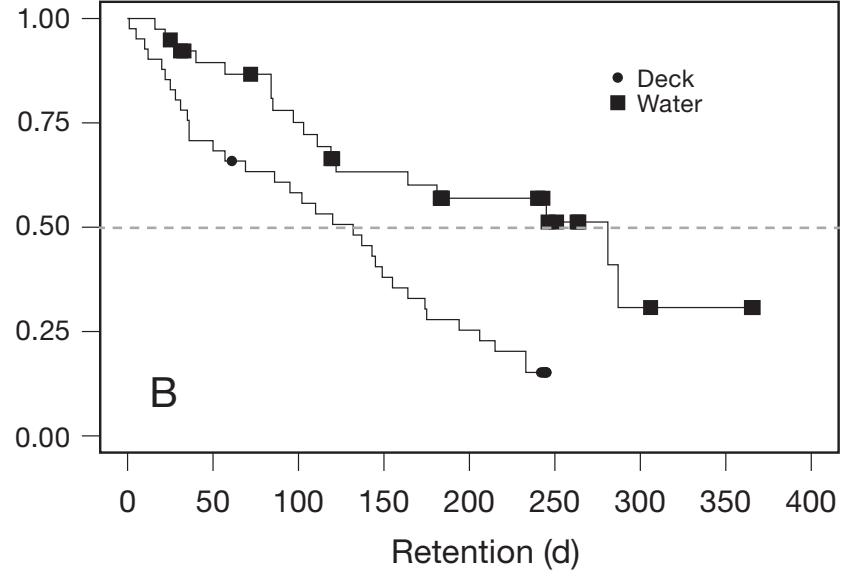

Fig. 5. (A) Kaplan-Meier (KM) survival curves of the proportion of pop-up satellite archival tags (PSATs) remaining attached until the programmed pop-up date, for 6 species of sharks, were significantly different (log likelihood ratio test (LLRT), $\chi^{2}=15.1, \mathrm{df}=5, \mathrm{p}=0.01$ ). (B) KM survival curves of sharks by method of attachment indicated the deck method yielded significantly worse retention than the in-water method (LLRT, $\chi^{2}=9.5, \mathrm{df}=1, \mathrm{p}=0.002$ ). (C) KM survival curves indicated significant differences (LLRT, $\chi^{2}=5.0, \mathrm{df}=2, \mathrm{p}=0.08$ ) by habitat class. See Fig. 4 for description of curves. Dashed line: 50th percentile

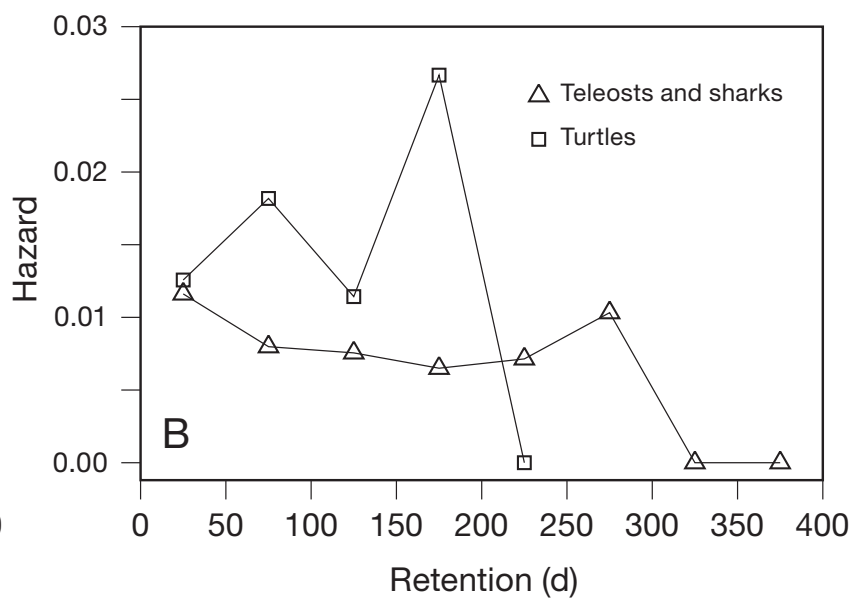

Fig. 6. (A) Kaplan-Meier survival curves of the proportion of pop-up satellite archival tags (PSATs) remaining attached until the programmed pop-up date, for turtles and non-turtles (see Fig. 4 for description of curves). Differences in survival curves were significant ( $\log$ likelihood ratio test, $\chi^{2}=6.9, \mathrm{df}=1, \mathrm{p}=0.009$ ). (B) Hazard functions estimated by the life table method, which involves grouping attachment times into $50 \mathrm{~d}$ intervals. Symbols represent the estimated hazard of early detachment at the midpoints of these intervals. Hazard functions are intimately related to survival curves: $h(t)=-\mathrm{d} / \mathrm{d} t \log (S(t))$, where $t$ is retention time and $S(t)$ is the proportion of PSATs retained (Allison 1995)

grammed pop-up date. The turtle hazard function (Fig. 6B) displayed a bimodal shape with peaks at $\sim 75$ and $175 \mathrm{~d}$, which suggested 2 modes of detachment failure.
Kaplan-Meier survival estimates of median retention times for sea turtles between geographic regions were significantly different (log likelihood ratio test, $\mathrm{p}=$ 0.019): Hawaii, 39 d ( $=16)$; Costa Rica, 49 d ( $\mathrm{n}=12)$; 
Brazil, 53 d ( $\mathrm{n}=8$ ); and California, $77 \mathrm{~d}(\mathrm{n}=10)$. Geographical region was the only significant risk factor identified for early PSAT detachment for turtles in $\mathrm{CPH}$ models. Brazil had a HR of 0.58 compared to Hawaii, Costa Rica versus Hawaii $(\mathrm{HR}=0.95)$ and California versus Hawaii $(H R=0.25)$. Only the California versus Hawaii comparison was significant $(p=0.004)$ with Hawaii deployments $\sim 4$ times more likely to detach prior to the programmed pop-up date.

\section{Quantity of data returned}

The 154 non-reporting PSATs were coded as returning zero data. Another 15 PSATs (physically recovered) successfully contacted Argos but did not return any satellite data. The mean $( \pm \mathrm{SE})$ data return for all de- ployments was $28 \pm 1$ data-days for temperature, $28 \pm$ 1 data-days for depth, and $27 \pm 1$ data-days for geolocation. Data return varied widely by species, habitat class and manufacturer (Table 1), and the geolocation datadays variable was positively correlated with retention $(\rho=0.56, p<0.001)$.

Boxplots of data-days for each of the 3 data types were plotted by length of the programmed pop-up period (Fig. 7). If data return was proportional to popup period, data-days would be approximately equal to the pop-up period. Instead, hump-shaped distributions were evident with a gradual decline in data-days for longer pop-up periods (Fig. 7). The boxplots also provide evidence of optimal pop-up periods.

The vertical intercepts of the ECDFs for MT were generally above those of WC except for deployments of 180 to 270 d (Fig. 8). The number of overall mean geo-
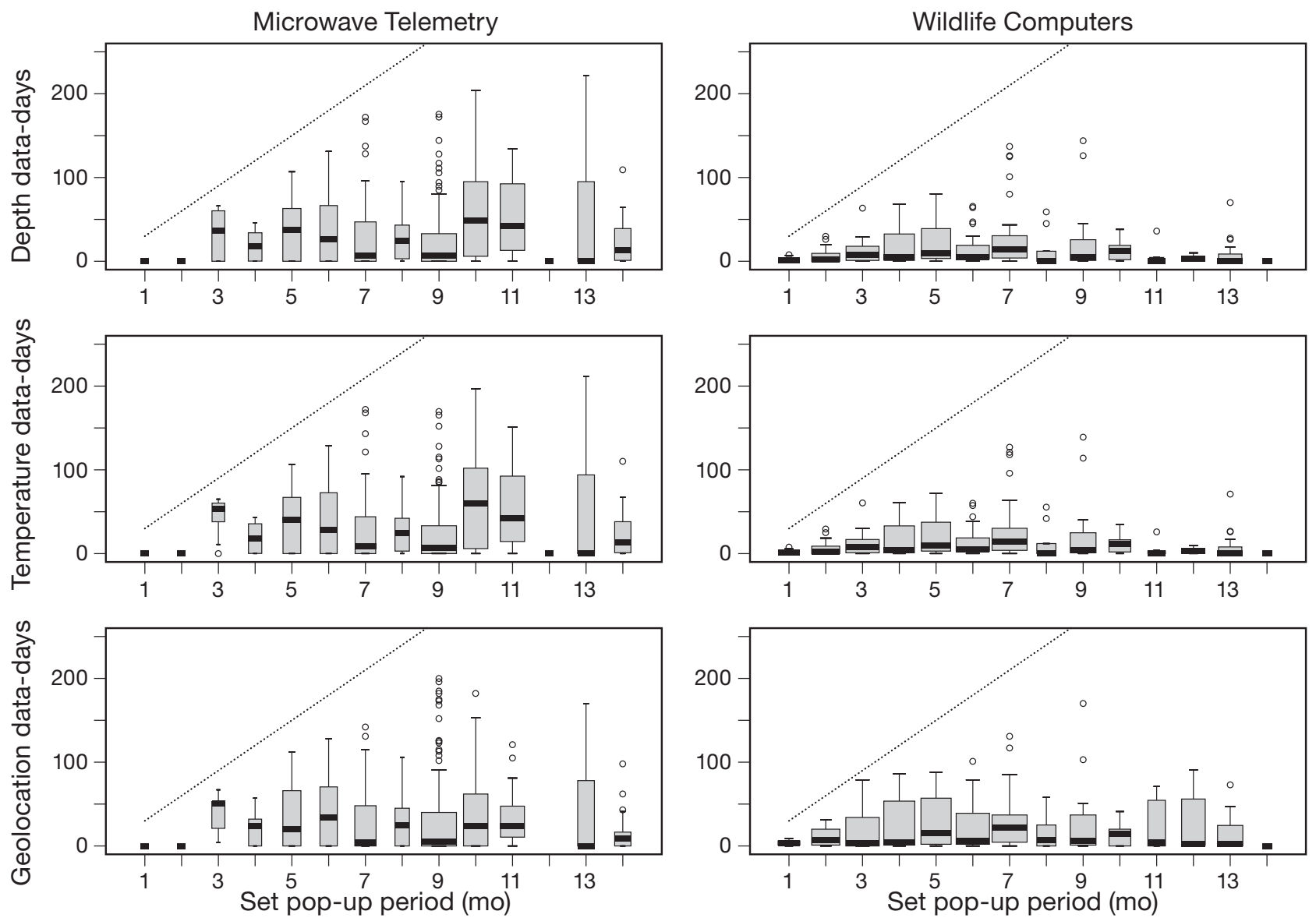

Fig. 7. Depth, temperature and geolocation data-days returned by pop-up satellite archival tag (PSAT) deployments versus popup period $\left(S\right.$ ). Data-days (data points $\mathrm{d}^{-1}$ ) are the raw data count (depth, temperature) or number of geolocations normalized by the data acquisition interval (i.e. the equivalent number of $24 \mathrm{~h}$ periods that the returned data would fill at the specified data acquisition interval without gaps). The thick horizontal bar is the median and the boxes contain $50 \%$ of the deployments (i.e. interquartile range [IQR]), with the upper and lower 'fence' representing $1.5 \times$ IQR. Outliers are represented with dots. The width of the box is proportional to the square root of the sample size. PSATs which failed to report were included and coded as zero data returned. The slanted dotted line represents the maximum possible amount of data return by month. Note that temperature and depth data reported by the PSATs are not directly comparable between manufacturers 

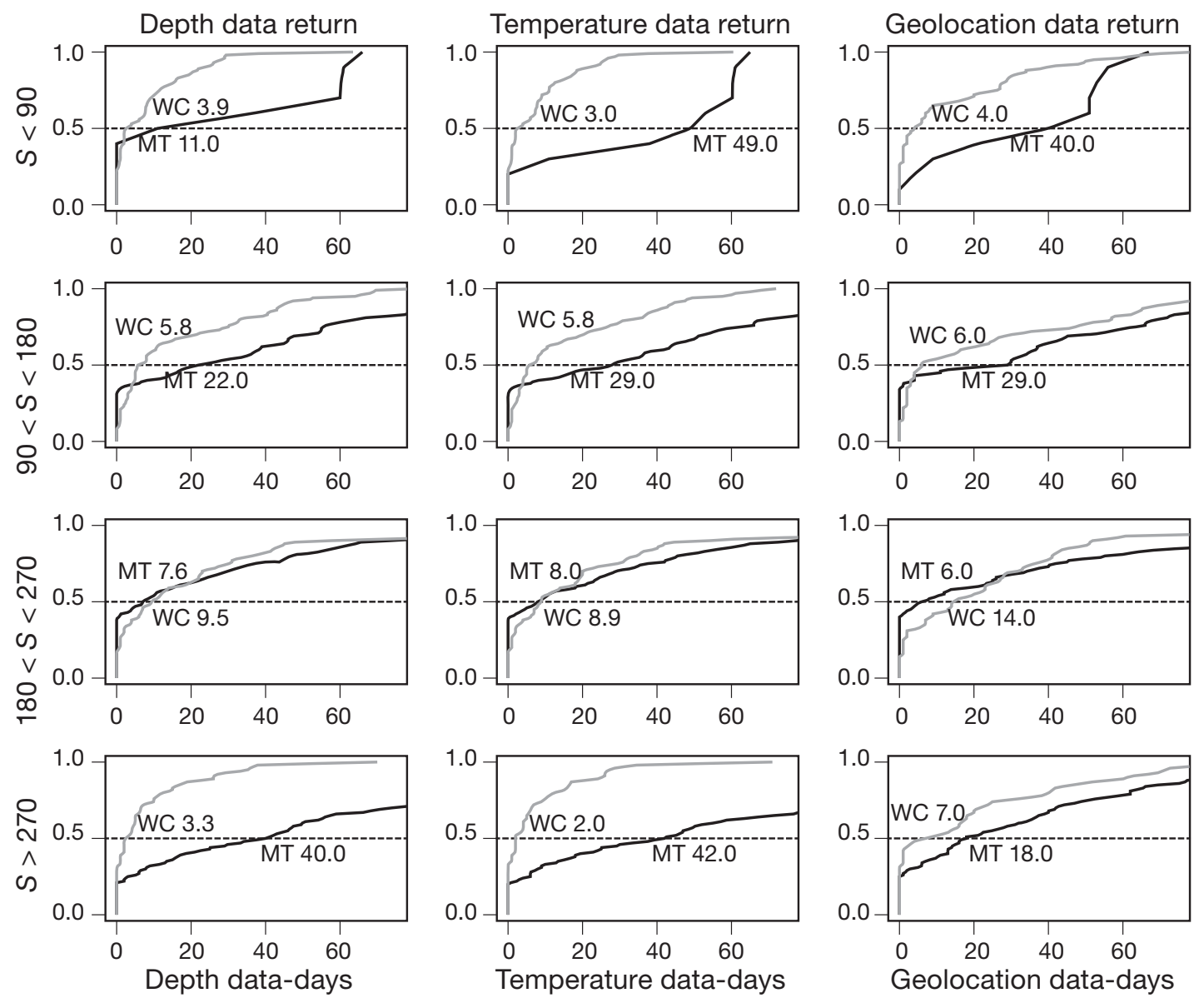

Fig. 8. Empirical cumulative distribution functions (ECDF) with proportion of PSAT deployments on the vertical axis and datadays returned on the horizontal axis (see Fig. 7 for a description of data-days). Deployments were grouped into pop-up periods ( $S$ ) ( $y$-axis) with lengths $<90 \mathrm{~d}, 90$ to $180 \mathrm{~d}, 180$ to $270 \mathrm{~d}$, and $>270 \mathrm{~d}$. Median data-days returned is the horizontal intersection at the 50th percentile (dashed line). PSATs which did not report are coded as zero data-days returned. The vertical intercepts at 0 datadays are the non-reporting rates. MT = Microwave Telemetry (black curves) and WC = Wildlife Computers (grey curves). Note that temperature and depth data reported by the PSATs are not directly comparable between manufacturers

location data-days returned was significantly higher for MT compared to WC ( $t$-test, $\mathrm{p}<0.001)$. More specifically, MT PSATs returned more geolocation data than WC PSATs for pop-up periods $<90 \mathrm{~d}$ ( $t$-test, $\mathrm{p}=0.006)$, between 90 and $180 \mathrm{~d}(\mathrm{p}<0.003)$, and $>270 \mathrm{~d}(\mathrm{p}<$ 0.001). However, MT PSATs were not significantly different from WC PSATs in terms of geolocation data returned for pop-up periods between 180 and $270 \mathrm{~d}$ $(\mathrm{p}=0.5)$.

The distributions of data types (segregated by species, habitat class, and PSAT manufacturer) all had positive skew. Skew was 1.95 for temperature, 2.03 for depth, and 1.84 for geolocation data. This positive skew can be seen in the ECDF plots (Fig. 8) which are almost all concave. The boxplots of data return (Fig. 7) also display this positive skew by having long upper whiskers representing the $25 \%$ of deployments which exceeded the 75 th percentile for data return. By con- trast, the lower whiskers were highly compressed due to the very large number of deployments of both manufacturers with minimal or no data return.

\section{Estimates of missing PSAT data}

Proportionally more data were lost from premature shedding of PSATs ( $M_{r}$ Eq. 5) than from recording and transmission failures $\left(M_{\mathrm{A}}\right.$, Eq. 6). Specifically, data loss $($ mean $\pm \mathrm{SE})$ for epipelagic species was $0.60 \pm 0.02\left(M_{r}\right)$ vs. $0.33 \pm 0.02\left(M_{\mathrm{A}}\right)(\mathrm{n}=388)$; for mesopelagic I species $0.47 \pm 0.05\left(M_{r}\right)$ vs. $0.41 \pm 0.04\left(M_{A}\right)(\mathrm{n}=98)$; and for mesopelagic II species $0.59 \pm 0.03\left(M_{r}\right)$ vs. $0.27 \pm 0.02$ $\left(M_{\mathrm{A}}\right)(\mathrm{n}=204)$. Segregated by manufacturer, data loss was $0.56 \pm 0.02\left(M_{r}\right)$ vs. $0.27 \pm 0.02\left(M_{\mathrm{A}}\right)(\mathrm{n}=427)$ for MT PSATs and $0.62 \pm 0.02\left(M_{r}\right)$ vs. $0.39 \pm 0.02\left(M_{\mathrm{A}}\right)(\mathrm{n}=$ 304) for WC PSATs. 


\section{Data density}

Data density as high as 24 points $\mathrm{d}^{-1}$ was obtained with MT PSATs programmed at data acquisition intervals of $0.25 \mathrm{~h}$ (Table 4). For WC PSATs, data acquisition intervals $\leq 4 \mathrm{~h}$ yielded optimal data-density when the pop-up period was $<270 \mathrm{~d}$, whereas intervals of $12 \mathrm{~h}$ (on the order of 1 point $\mathrm{d}^{-1}$ ) were optimal for pop-up periods $>270 \mathrm{~d}$ (Table 4 ).

\section{Data return models}

Data-days for temperature $(\rho=-0.17, p<0.0001)$ and depth $(\rho=-0.18, p<0.0001)$ showed a moderate negative correlation with the age of the PSAT at deployment, which suggests that older tags tended to return

Table 4. Pop-up satellite archival tag (PSAT) data density (mean \pm SE) summarized by set pop-up period, data acquisition interval, no. of PSATs depioyed and by PSAT manufacturer (Microwave Telemetry and Wildlife Computers). Data density is the average number of data points of each type (i.e. depth, geolocation, temperature) per day of deployment (see Eq. 4). Note that data density is not directly comparable between manufacturers

\begin{tabular}{|c|c|c|c|}
\hline $\begin{array}{l}\text { Pop-up } \\
\text { period (d) }\end{array}$ & $\begin{array}{l}\text { Data interval } \\
\text { (h) }\end{array}$ & $\begin{array}{c}\text { No. of PSATs } \\
\text { deployed }\end{array}$ & $\begin{array}{l}\text { Data density } \\
\text { (points day }^{-1} \text { ) }\end{array}$ \\
\hline \multicolumn{4}{|c|}{ Microwave Telemetry } \\
\hline$<90$ & 1 & 11 & $10.1 \pm 2.1$ \\
\hline $90-180$ & 1 & 56 & $8.1 \pm 0.9$ \\
\hline \multirow[t]{2}{*}{$180-270$} & 0.25 & 51 & $24.6 \pm 3.4$ \\
\hline & 1 & 148 & $6.9 \pm 0.6$ \\
\hline$>270$ & 1 & 157 & $8.2 \pm 0.5$ \\
\hline \multicolumn{4}{|c|}{ Wildlife Computers } \\
\hline \multirow[t]{7}{*}{$<90$} & 1 & 19 & $4.6 \pm 0.8$ \\
\hline & 2 & 22 & $4.7 \pm 0.6$ \\
\hline & 3 & 2 & $2.1 \pm 0.08$ \\
\hline & 4 & 9 & $3.2 \pm 0.5$ \\
\hline & 6 & 1 & 2.7 \\
\hline & 12 & 6 & $1.2 \pm 0.2$ \\
\hline & 24 & 1 & 0.3 \\
\hline \multirow[t]{7}{*}{$90-180$} & 1 & 9 & $0.6 \pm 0.2$ \\
\hline & 2 & 9 & $3.5 \pm 0.9$ \\
\hline & 3 & 1 & 5.5 \\
\hline & 4 & 1 & 1.7 \\
\hline & 6 & 11 & $1.3 \pm 0.3$ \\
\hline & 12 & 51 & $1.1 \pm 0.07$ \\
\hline & 24 & 5 & $0.8 \pm 0.1$ \\
\hline \multirow[t]{4}{*}{$180-270$} & 1 & 8 & $2.0 \pm 1.0$ \\
\hline & 6 & 13 & $1.5 \pm 0.3$ \\
\hline & 12 & 28 & $1.1 \pm 0.1$ \\
\hline & 24 & 16 & $0.5 \pm 0.08$ \\
\hline \multirow[t]{4}{*}{$>270$} & 1 & 17 & $1.1 \pm 0.4$ \\
\hline & 6 & 1 & 0 \\
\hline & 12 & 1 & 1.4 \\
\hline & 24 & 27 & $0.63 \pm 0.07$ \\
\hline
\end{tabular}

fewer temperature and depth data, but other factors were probably more influential (Table 5). The number of geolocation data-days was not significantly correlated with tag age $(\rho=-0.006, p=0.875)$. The quantity of temperature, depth, and geolocation data returned, however, was positively correlated with the tag production year, indicating improvement of PSAT performance over time $(\rho=0.12, p=0.001$ for temperature; $\rho=0.12, p=0.001$ for depth; and $\rho=0.21, p<0.0001$ for geolocation). Moreover, models of optimal data return for MT and WC PSATs (Table 5) showed that tag production year was a positive term, thus confirming that data return has increased over time.

Optimum pop-up periods, which maximize the number of geolocation data-days returned, were $372 \mathrm{~d}$ for MT PSATs and $146 \mathrm{~d}$ for WC PSATs (Table 5), and these optimal periods were further refined by data type using resampling methods (Table 6). Assuming tag production year was 2004 (most recent year in the data set), the expected value of the optimal number of geolocation data-days $\left(n_{\mathrm{L}}^{*}\right)$ was 30.6 for MT PSATs and 14.1 for WC PSATs, and was found by evaluating Model 5 (Table 5). These expected values were the averages of data-days returned and included the zero data-days from non-reporting PSATs. Model-predicted geolocation data-days suggested improved data return over time (Fig. 9). The significant density dependence for both MT and WC indicates that the expected geolocation data return decreased if the pop-up period was longer than the optimum (Table 5). This decline should be understood to be 'on average', accounting for some PSATs which failed to report and others with weak data transmission (presumably due to low battery power and/or biofouling of the antennae).

\section{Meta-analysis of PSAT performance}

The overall PSAT reporting rate in the literature (summarized by bootstrap analysis in Table 7 and Figs. S2 \& $\mathrm{S} 3$ in the supplement at www.int-res.com/articles/suppl/ m433p001_supp.pdf) was $76 \%$ (95\% bootstrap CI $=73$ to $78 \%)$, which was not significantly different $(p=0.5)$ from the authors' database (reporting rate $=76 \%, 95 \%$ bootstrap CI $=72$ to $79 \%$ ). From the literature review, 32 studies with $100 \%$ reporting PSATs made up the base of the funnel plot that summarizes PSAT reporting rates versus sample sizes (n) for $\mathrm{n}<20$ (Fig. 10). Variability in PSAT reporting rates from published studies were further explored with log likelihood ratio tests and increasing habitat class (i.e. with increasing depth) was found to be a significant risk factor $(\mathrm{OR}=0.817, \mathrm{p}=0.011)$. Journal publication year (tag production year was unavailable in the literature sources) was also identified as a significant risk factor, with reporting rates decreasing over time 
Table 5. Models of geolocation data return for Microwave Telemetry $(\mathrm{n}=427)$ and Wildlife Computers $(\mathrm{n}=304)$ pop-up satellite archival tags (PSATs). Geolocation data-days $\left(n_{\mathrm{L}}^{\prime}\right)$ are normalized by the data acquisition interval (i.e. the equivalent number of $24 \mathrm{~h}$ periods that the returned data would fill at the specified data acquisition interval without gaps) where habitat class $(D)$, tag production year $(Y)$, tag age $(A)$ and pop-up period $(S)$ are variables. Parameter $a$ is the intercept, parameter $b$ is the decay rate (describing how data return declines for longer pop-up periods), and parameters $c, d$, and e describe the effects of habitat class, tag production year and age of PSAT at deployment, respectively. The existence of an optimum pop-up period is tested where the null hypothesis is $b=0$ (if $\mathrm{p}<0.05$, then it implies the existence of an optimal pop-up period). The optimal pop-up period ( $\left.S^{*}\right)$ is given by Eq. (9). The expected value of data-days is $n^{*}$ when the pop-up period is optimized at $S^{*}$. Lower AIC values indicate better model fit. na = not available

\begin{tabular}{|c|c|c|c|c|c|c|}
\hline Model description & $\mathrm{AIC}$ & $\begin{array}{c}\text { Model } \\
\text { coefficient }\end{array}$ & Estimate \pm SE & $\mathrm{p}$ & $S^{*}$ & $n^{*}$ \\
\hline \multicolumn{7}{|l|}{$\begin{array}{l}\text { Microwave Telemetry } \\
\text { Model } 1\end{array}$} \\
\hline $\begin{array}{l}\text { Beverton-Holt }{ }^{\mathrm{A}}: n_{\mathrm{L}}^{\prime} \approx \text { Pop-up period } \\
\log \left(n_{\mathrm{L}}^{\prime}+1\right) \approx a+\log (S)-\log (1+b S)\end{array}$ & 1743 & $\begin{array}{l}a \\
b\end{array}$ & $\begin{array}{l}2.805 \pm 59.9 \\
1.725 \pm 103.5\end{array}$ & na & na & na \\
\hline $\begin{array}{l}\text { Model } 2 \\
\text { Ricker }{ }^{\mathrm{B}}: n_{\mathrm{L}}^{\prime} \approx \text { Pop-up period } \\
\log \left(n_{\mathrm{L}}^{\prime}+1\right) \approx a+\log (S)+b S\end{array}$ & 1746 & $\begin{array}{l}a \\
b\end{array}$ & $\begin{array}{r}-2.062 \pm 0.3064 \\
-0.0046 \pm 0.0012\end{array}$ & $<0.0001$ & 217 & 9.2 \\
\hline $\begin{array}{l}\text { Model } 3 \\
\text { Ricker }: n_{L}^{\prime} \approx \text { Pop-up period }+ \text { Tag age } \\
\log \left(n_{L}^{\prime}+1\right) \approx a+\log (S)+b S+e A\end{array}$ & 1745 & $\begin{array}{l}a \\
b \\
e\end{array}$ & $\begin{array}{r}-2.132 \pm 0.3525 \\
-0.0413 \pm 0.0012 \\
0.00079 \pm 0.0005\end{array}$ & $<0.001$ & 242 & $7.8^{\mathrm{C}}$ \\
\hline $\begin{array}{l}\text { Model } 4 \\
\text { Ricker }: n_{L}^{\prime} \approx \text { Pop-up period }+ \text { Habitat class } \\
\log \left(n_{\mathrm{L}}^{\prime}+1\right) \approx a+\log (S)+b S+c D\end{array}$ & 1730 & $\begin{array}{l}a \\
b \\
c\end{array}$ & $\begin{array}{r}-1.723 \pm 0.3106 \\
-0.0026 \pm 0.0013 \\
-0.419 \pm 0.0998\end{array}$ & 0.021 & 385 & $15.6^{\mathrm{D}}$ \\
\hline $\begin{array}{l}\text { Model } 5 \\
\text { Ricker }: n_{\mathrm{L}}^{\prime} \approx \text { Pop-up period + Production year } \\
\log \left(n_{\mathrm{L}}^{\prime}+1\right) \approx a+\log (S)+b S+d Y\end{array}$ & 1722 & $\begin{array}{l}a \\
b \\
d\end{array}$ & $\begin{aligned}-1021.7 & \pm 203.0 \\
-0.0027 & \pm 0.0012 \\
0.509 & \pm 0.1013\end{aligned}$ & 0.015 & 372 & $30.6^{\mathrm{E}}$ \\
\hline $\begin{array}{l}\text { Wildlife Computers } \\
\text { Model } 1\end{array}$ & 1137 & $\begin{array}{l}a \\
b\end{array}$ & $\begin{array}{r}0.0647 \pm 0.0606 \\
-0.5158 \pm 0.8249\end{array}$ & na & na & na \\
\hline Model 2 & 1135 & $\begin{array}{l}a \\
b\end{array}$ & $\begin{array}{r}-1.7087 \pm 0.1761 \\
-0.00672 \pm 0.0009\end{array}$ & $<0.0001$ & 149 & 8.9 \\
\hline Model 3 & 1135 & $\begin{array}{l}a \\
b \\
e\end{array}$ & $\begin{array}{r}-1.768 \pm 0.1895 \\
-0.00685 \pm 0.0009 \\
0.000565 \pm 0.0005\end{array}$ & $<0.0001$ & 146 & $8.2^{\mathrm{C}}$ \\
\hline Model 4 & 1132 & $\begin{array}{l}a \\
b \\
c\end{array}$ & $\begin{aligned}-1.952 & \pm 0.2120 \\
-0.00715 & \pm 0.0009 \\
0.2896 & \pm 0.1300\end{aligned}$ & $<0.0001$ & 140 & $8.8^{\mathrm{D}}$ \\
\hline Model 5 & 1126 & $\begin{array}{l}a \\
b \\
d\end{array}$ & $\begin{aligned}-270.6 & \pm 129.2 \\
-0.00687 & \pm 0.0009 \\
0.1344 & \pm 0.0646\end{aligned}$ & $<0.0001$ & 146 & $14.1^{\mathrm{E}}$ \\
\hline
\end{tabular}

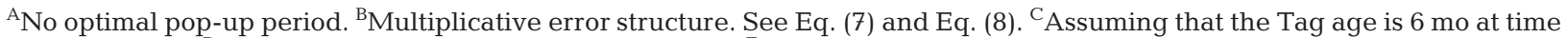
of deployment. ${ }^{\mathrm{D} A s s u m i n g}$ that habitat class is epipelagic. ${ }^{\mathrm{E}}$ Assuming that year is 2004 , the most recent year in the data set

Table 6. Optimal set pop-up period $\left(S^{*}\right)$ and $95 \%$ bootstrap confidence intervals by PSAT manufacturer and data type. Note that temperature and depth data reported by the PSATs are not directly comparable between manufacturers

\begin{tabular}{|lcccc|} 
Data type & \multicolumn{2}{c|}{ Wildlife Computers } & \multicolumn{2}{c|}{ Microwave Telemetry } \\
& $S^{*}(\mathrm{~d})$ & $95 \% \mathrm{CI}$ & $S^{*}(\mathrm{~d})$ & $95 \%$ CI \\
\hline Depth & 124 & $119-129$ & 354 & $317-405$ \\
Temperature & 125 & $119-130$ & 311 & $281-345$ \\
Geolocation & 145 & $138-152$ & 320 & $291-357$ \\
\hline
\end{tabular}

$(\mathrm{OR}=0.746, \mathrm{p}<0.0001)$. In the literature studies, manufacturer was not a significant risk factor in PSAT reporting rates $(\mathrm{p}=0.728)$.

Log likelihood ratio tests showed that the overall PSAT reporting rates from the literature review and the authors' database were not significantly different $\left(\chi^{2}=2.299, p=0.130\right)$. PSAT reporting rates by manufacturer, however, were significantly different between data sources (literature versus authors' database; $\left.\chi^{2}=14.28, p<0.001\right)$. In the literature review, the reporting rates segregated by manufacturer were both 


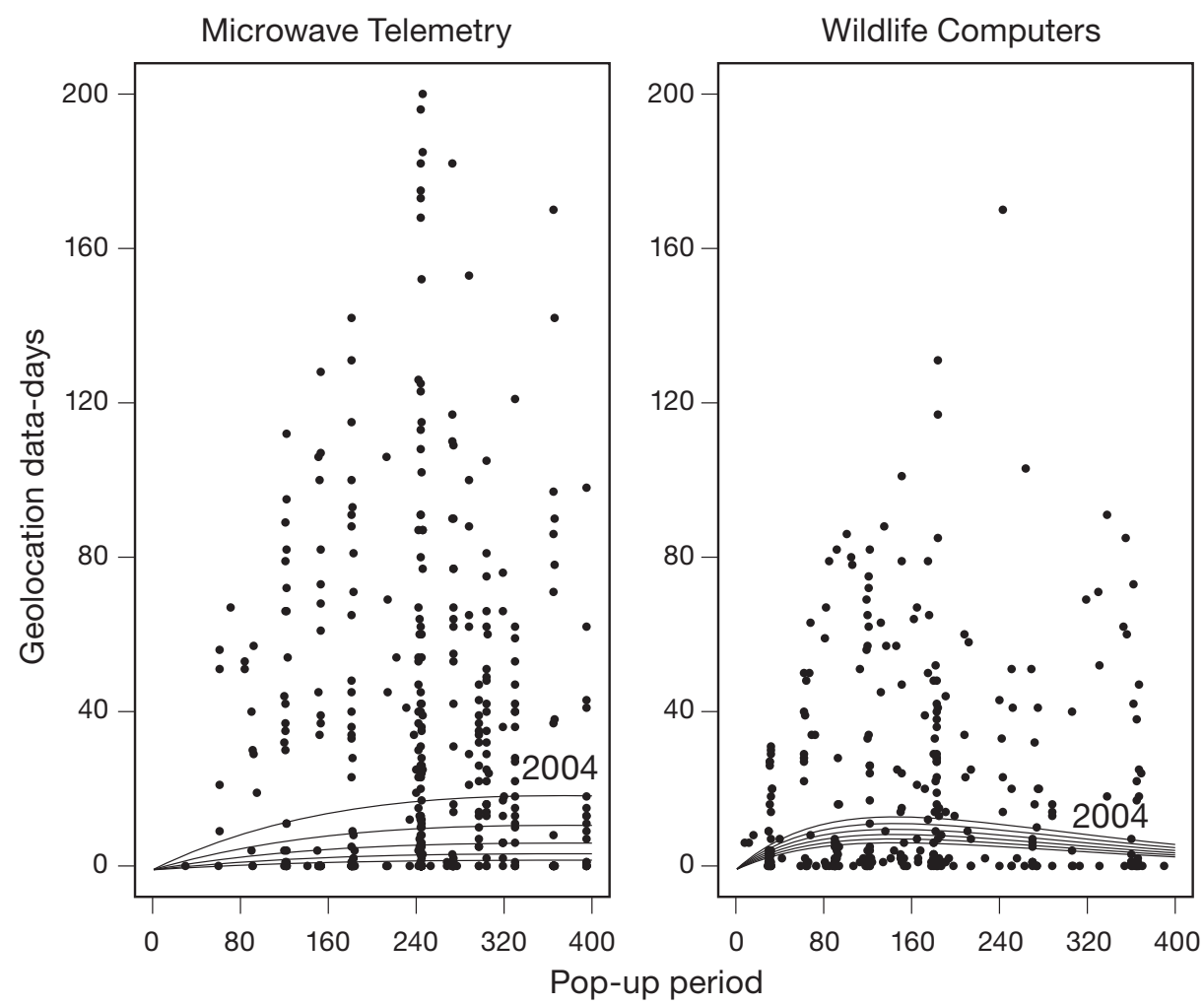

Fig. 9. Relationship of geolocation data-days returned from pop-up satellite archival tags (PSATs) versus pop-up period $(S)$ as determined from the best-fitting model (No. 5) for the years 2000 to 2004 (see Table 5). Symbols are the raw data points, and fitted curves are contour lines on the response surface with a different curve for each year (due to overlap on the contour lines, only the most recent year is labeled). The optimum pop-up periods are $S^{*}=372$ for Microwave Telemetry $(\mathrm{n}=427)$ and $S^{*}=146$ for Wildlife Computers $(\mathrm{n}=304)$. The fitted curves represent expected values of geolocation data-days returned, including the failed deployments, which appear on the horizontal axis with zero data-days returned

very close to $76 \%$, in contrast to the results from the authors' database, where WC PSATs $(87 \%)$ were higher than MT PSATs (73\%).

PSAT reporting rates by habitat class were not significantly different between data sources $\left(\chi^{2}=3.41, \mathrm{p}<\right.$ 0.07). A log likelihood ratio test comparing the 11 species common to both data sources showed significant differences in reporting rates (Table 8). Epipelagic species exhibited nearly identical reporting rates in both sources of data. The reporting rates of mesopelagic I species were also not significantly different between the authors' database and the literature review. The mesopelagic II species, taken as a group, did not show any significant differences in reporting rates, yet each individual species comparison had significantly different reporting rates between the 2 data sources (Table 8). Reciprocals of PSAT reporting rates from both the authors' database and published literature for all species, calculated to help with sampling designs, are provided in Table $\mathrm{S} 6$ in the supplement.

\section{DISCUSSION}

To the best of our knowledge, our analysis includes $\sim 50 \%$ of all PSAT deployments worldwide and covers a broad array of marine species. Our intent was to provide comprehensive analyses of PSAT performance and reliability, with the ultimate goal of helping investigators design better studies by identifying risk factors. We anticipated that manufacturers would also benefit from this study. Meeker \& Escobar (1998) and Cannon \& Edmondson (2005) argue that analysis of failure is critical to better understand emerging technology and to improve experimental design. However, Cannon \& Edmondson (2005) argued that psychological and social ramifications stigmatize failure, which tends to discourage this kind of analysis. In other words, there is a negative connotation attached to reporting failure. For example, Gunn \& Block (2001) warn of potential social and monetary consequences for reporting electronic tag failure in fisheries research. Therefore, instead of merely writing off failures to 'uncontrollable events', Cannon \& Edmondson (2005) suggest analyzing failure in a systematic framework, which we attempted to do in this report. Information on failed attempts can be just as important as information from reporting PSATs.

\section{Model performance and power}

Due to significant individual variability in pelagic animals (e.g. Arnold \& Dewar 2001, Gunn \& Block 2001, Musyl et al. 2003, 2011, Bestley et al. 2009), and because many species had only one or a few deploy- 
Table 7. Summary of bootstrap reporting rates for pop-up satellite archival tag (PSAT) found in the literature, organized by habitat class and species. A binomial distribution was assumed with study-wise reporting rates and sample sizes taken from the literature review (Table S2 in the supplement at www.intres.com/articles/suppl/m433p001_supp.pdf). Reporting rates were resampled 3000 times, and after each iteration, the reporting rate by species was recomputed. The median of the bootstrap distribution yielded a point estimate for the reporting rates $\pm \mathrm{SE}$. Confidence limits used were the 2.5th and 97.5th percentile of each species' bootstrap distributions. Bigeye thresher shark, Greenland shark, sharptail mola, shortfin mako shark and tiger shark all had $100 \%$ reporting rates and were not included in this analysis. In 53 published articles, results from multiple years, or multiple types of deployments were referred to as 'studies' ( $\mathrm{n}=81$ studies)

\begin{tabular}{|lcccc|}
\hline & $\begin{array}{c}\text { No. of PSATs } \\
\text { deployed }\end{array}$ & $\begin{array}{c}\text { No. of } \\
\text { studies }\end{array}$ & $\begin{array}{c}\text { PSAT reporting rate } \\
\text { (median } \pm \text { SE) }\end{array}$ & $\begin{array}{c}\text { Confidence } \\
\text { interval }\end{array}$ \\
\hline Coastal & & & & \\
Longfinned eel & 14 & 2 & $0.79 \pm 0.10$ & $0.57-1.00$ \\
$\begin{array}{l}\text { Epipelagic } \\
\text { Blue marlin }\end{array}$ & 48 & 9 & $0.72 \pm 0.05$ & $0.63-0.82$ \\
Black marlin & 7 & 2 & $0.75 \pm 0.14$ & $0.50-1.00$ \\
Albacore tuna & 6 & 1 & $0.33 \pm 0.19$ & $0.00-0.67$ \\
Sailfish & 58 & 3 & $0.83 \pm 0.04$ & $0.75-0.92$ \\
White marlin & 77 & 6 & $0.86 \pm 0.04$ & $0.79-0.92$ \\
Striped marlin & 86 & 3 & $0.85 \pm 0.04$ & $0.78-0.92$ \\
Total & 282 & 24 & $0.81 \pm 0.02$ & $0.77-0.85$ \\
Mesopelagic I & & & & \\
Great white shark & 64 & 5 & $0.73 \pm 0.05$ & $0.62-0.83$ \\
Blue shark & 28 & 3 & $0.61 \pm 0.08$ & $0.43-0.75$ \\
Whale shark & 21 & 3 & $0.67 \pm 0.10$ & $0.48-0.86$ \\
Total & 113 & 11 & $0.70 \pm 0.04$ & $0.62-0.78$ \\
Mesopelagic II & & & & \\
Halibut & 14 & 1 & $0.36 \pm 0.13$ & $0.14-0.57$ \\
Leatherback turtle & 61 & 1 & $0.52 \pm 0.06$ & $0.39-0.64$ \\
Basking shark & 25 & 2 & $0.48 \pm 0.08$ & $0.32-0.64$ \\
Bigeye tuna & 31 & 4 & $0.90 \pm 0.05$ & $0.81-0.97$ \\
Opah & 17 & 2 & $0.94 \pm 0.06$ & $0.82-1.00$ \\
Bluefin tuna & 549 & 13 & $0.78 \pm 0.14$ & $0.75-0.81$ \\
Salmon shark & 40 & 4 & $0.80 \pm 0.06$ & $0.68-0.92$ \\
Swordfish & 31 & 2 & $0.77 \pm 0.07$ & $0.61-0.90$ \\
Total & 768 & 29 & $0.75 \pm 0.01$ & $0.73-0.78$ \\
\hline
\end{tabular}

ments, it was not practical to include species-specific behaviours separately in the models. Not only was grouping of sparsely represented species considered essential, but grouping species into ordinal habitat classes also increased the power of statistical inference (Agresti 2002). To estimate effects for 19 species in the authors' database requires $18(19-1)$ parameters, while for the ordinal habitat classes only 1 parameter is required (Agresti 2002). If not grouped, underrepresented species would need to be excluded from our models, which would further reduce power by reducing the sample size. Moreover, PSAT reporting models that include species as a term fail to converge, and PSAT retention models including the species term are outperformed by habitat class models (data not shown). The appropriateness of our habitat class groupings was based on empirical data on vertical movement and distribution patterns (e.g. Musyl et al. 2004, 2011, Bernal et al. 2009). We also argue that models with habitat class can be useful when considering new PSAT deployments on species not represented in the database. In summary, by using habitat class, we avoided these non-convergence and power issues and also constructed more useful models.

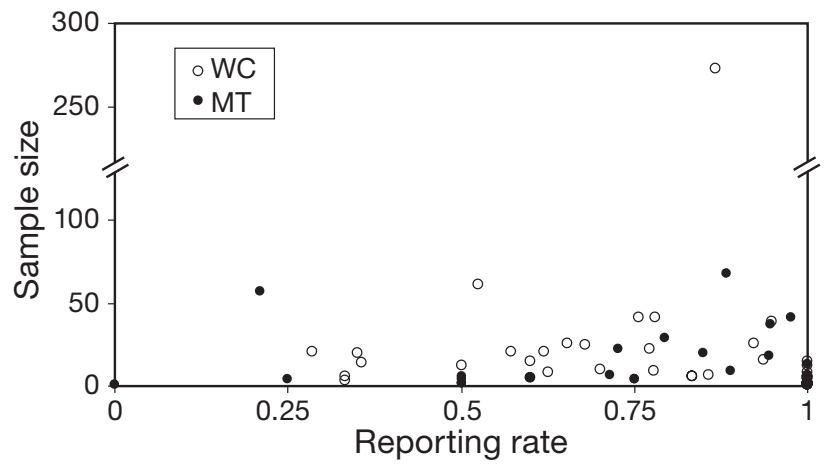

Fig. 10. Funnel plot of sample size against pop-up satellite archival tag (PSAT) reporting rate in the literature review (Table S2 in the supplement at www.int-res.com/articles/ suppl/m433p001_supp.pdf). The funnel plot was used to evaluate publication bias and reporting bias in the meta-analysis. The overall PSAT reporting rate was $\hat{p}=0.76$. MT $=$ Microwave Telemetry, WC $=$ Wildlife Computers

\section{Risk factors associated with PSAT reporting rates}

Although many factors may alter habitat and depth preferences of pelagic species over temporal and spatial scales (Parin 1970, Arnold \& Dewar 2001, Gunn \& Block 2001, Musyl et al. 2003, 2011, Wilson et al. 2005, Schaefer et al. 2007, Bernal et al. 2009), our results suggest there is a threshold where PSAT reporting rates are compromised by pressure or temperature changes accompanying changes in depth. Several authors have also suggested that rapid changes in temperature and pressure accompanying extensive vertical movements could compromise PSAT performance (Sedberry \& Loefer 2001, Benson \& Dutton 2005, Wilson et al. 2006, Weng et al. 2007). The interaction between habitat class and PSAT manufacturer was prominent, and single species models would have missed this discovery. As importantly however, both PSAT manufacturers 
Table 8. Comparison of reporting rates by pop-up satellite archival tag (PSAT) between the authors' database and literature review (see Table S2 in the supplement at www.int-res.com/articles/suppl/m433p001_supp.pdf), organized by habitat class and species. p-values are derived from hypothesis tests comparing 2 proportions

\begin{tabular}{|c|c|c|c|c|c|}
\hline & $\begin{array}{l}\text { Authors' } \\
\text { Reporting } \\
\text { rate }\end{array}$ & $\begin{array}{c}\text { database } \\
\text { No. of } \\
\text { PSATs } \\
\text { deployed }\end{array}$ & $\begin{array}{c}\text { Literature } \\
\text { Reporting } \\
\text { rate }\end{array}$ & $\begin{array}{l}\text { review } \\
\text { No. of } \\
\text { PSATs } \\
\text { deployed }\end{array}$ & $\mathrm{p}$ \\
\hline \multicolumn{6}{|l|}{ Epipelagic } \\
\hline Blue marlin ${ }^{\mathrm{a}}$ & 0.83 & 48 & 0.72 & 65 & 0.077 \\
\hline Striped marlin ${ }^{\mathrm{a}}$ & 0.82 & 202 & 0.85 & 86 & 0.283 \\
\hline Black marlin ${ }^{\mathrm{b}}$ & 0.86 & 57 & 0.75 & 8 & 0.258 \\
\hline Total $^{\mathrm{a}}$ & 0.83 & 307 & 0.73 & 159 & 0.162 \\
\hline \multicolumn{6}{|l|}{ Mesopelagic I } \\
\hline Blue shark ${ }^{\mathrm{a}}$ & 0.50 & 32 & 0.61 & 28 & 0.201 \\
\hline Great white shark ${ }^{\mathrm{a}}$ & 0.75 & 48 & 0.73 & 64 & 0.426 \\
\hline Total $^{\mathrm{a}}$ & 0.65 & 80 & 0.70 & 92 & 0.738 \\
\hline \multicolumn{6}{|l|}{ Mesopelagic II } \\
\hline Bluefin tuna ${ }^{a}$ & 0.86 & 146 & 0.78 & 549 & 0.007 \\
\hline Swordfish $^{\mathrm{a}}$ & 0.47 & 38 & 0.77 & 31 & 0.003 \\
\hline Basking shark ${ }^{\mathrm{b}}$ & 0.00 & 1 & 0.48 & 25 & 0.001 \\
\hline Bigeye thresher shark ${ }^{b}$ & $\begin{array}{ll}\mathrm{x}^{\mathrm{b}} & 0.38\end{array}$ & 8 & 1.00 & 2 & 0.001 \\
\hline Bigeye tuna $^{b}$ & 0.50 & 6 & 0.90 & 31 & 0.019 \\
\hline Shortfin mako shark ${ }^{b}$ & 0.40 & 5 & 1.00 & 1 & 0.001 \\
\hline Total $^{\mathrm{a}}$ & 0.74 & 204 & 0.78 & 639 & 0.185 \\
\hline
\end{tabular}

sure and/or temperature, and a role of biological fouling in reducing retention time. For pop-up latitude, the HR for risk of early PSAT detachment was reduced 0.886 for every $10^{\circ}$ increase in latitude. This trend was evident over the entire range of latitudes and was concordant with the horizontal distribution patterns of chlorophyll a (chl $a_{\text {; }}$ see Figs. S4 \& S5 in the supplement). In support of these ideas, movement patterns of marine turtles tagged with Argoslinked, sattelite-relayed data loggers in the Atlantic displayed varying transmission cycles that were correlated with saltwater switch performance, which Hays et al. (2007) concluded was related to biofouling. Fouling organisms that accumulate on the tags in southern waters would die off as the tagged animal moved into much cooler, northern waters. In a movement study on basking sharks, Hays et al. (2007) also reported that PSATs with shorter deployment durations were less likely to fail than PSATs programmed for longer durations. We therefore argue that biofouling is a plausible additive risk factor,

have improved tag performance over time. The hypothesis of a 'bad production lot' of PSATs was tested by the sequence of successes and failures ordered by tag production serial numbers for each manufacturer. We found no evidence of non-randomness in these sequences that could not otherwise be explained by habitat class effects. Surprisingly, tag age (hypothesized to be a strong risk factor due to biofouling, battery drain, passivation, and exposure to pressure- and temperature-related risks over time) was not significantly correlated with tag failure.

\section{Risk factors associated with PSAT retention times}

Teleosts and sharks

The best-fitting $\mathrm{CPH}$ model for retention times (when PSATs were affixed by tag head) had a strong interaction between habitat class and latitude. The HR for the interaction between habitat class and latitude suggests that PSAT retention times increase away from the equator and for animals in deeper habitats. Latitude and habitat class were probably capturing different aspects of the species variable, and species displayed distinct meridional trends in PSAT retention time. The risk factors behind this trend are likely presas accumulation of fouling organisms on the PSAT over time would add extra drag and accelerate tag shedding. Indeed, Hays et al. (2007) referred to biofouling as the 'Achilles heel' of satellite tags.

PSAT retention time was also inversely related to vertical distribution of chl a. Epipelagic species, which had the poorest retention times, spend significantly more time in the photic zone ( 150 to $200 \mathrm{~m})$, where the vertical distribution of chl $a$ is at its highest concentration (Marshall 1966, Furuya 1990, Longhurst 1998, Seki et al. 2002, Pérez et al. 2006). Therefore, unless epipelagic species migrate into deeper (>200 m) and cooler waters for extended periods, or away from areas with high chl a concentration, the opportunity for fouling organisms to accumulate on PSATs, as opposed to those devices being carried by deeper-diving species, is likely greater. Moreover, oscillations of pressure and temperature delay the establishment of fouling organisms (Zobell \& Johnson 1949, Zobell \& Oppenheimer 1950, Pope \& Berger 1973, Johnson et al. 1974, Yayanos et al. 1983, Trent \& Yayanos 1985). Furthermore, our observation that July, August, and September were the riskiest months for PSAT retention (Figs. S4 \& S5 in the supplement) matched seasonal abundance patterns in chl a (Longhurst 1998).

The theory that biofouling influenced retention times can be further extended by hypothesizing that some 
fouling organisms cause localized infection at the PSAT anchoring site. The forces of lift and drag on PSATs are maximized at the anchor point (i.e. tag head). Drag, chafing, abrasion, vibration, and movement of tether and tag head (and possibly wicking action of the tether) most likely delay tag-insertion wound healing, thereby creating opportunity for infection, inflammation, tissue necrosis, and eventual PSAT shedding (Roberts et al. 1973a,b,c, Borucinska et al. 2001, 2002, Jellyman \& Tsukamoto 2002, Prince et al. 2002, Thorsteinsson 2002, De Metrio et al. 2004, Grusha \& Patterson 2005, Wilson et al. 2005).

Our best-fitting retention models indicated that nylon tag heads were more likely to detach early than other types of tag heads, but other factors were also important; tag head type was strongly associated with tagger, tether material, location, and species/habitat class. Therefore, retention times are most likely a complex function that includes many factors (e.g. biomaterial compatibility, tissue rejection, surface area, biofouling, and infection). Neilson et al. (2009) reported retention times $>400 \mathrm{~d}$ in swordfish where PSATs were attached with nylon tag heads. To our knowledge, this is the longest documented retention of PSATs for any species. However, emphasizing outliers when examining expected PSAT retention can be misleading. For example, PSATs in Neilson et al. (2009) had a median retention of $48 \mathrm{~d}$, which is essentially the value we calculated for swordfish (50 d). Moreover, our models (Table 3) predict that deep divers such as swordfish should exhibit increased retention when tagged in temperate latitudes compared to tropical latitudes regardless of tag head. Furthermore, we tested the PSAT retention survival curves for nylon tag heads from data in Neilson et al. (2009) (median retention $[95 \% \mathrm{CI}]=48 \mathrm{~d}$ [23 to $119 \mathrm{~d}$ ]) against our data set (36 d [28 to 54]) and found no significant differences ( $\log$ likelihood ratio test, $\mathrm{p}=0.35$ ). The median is robust to outliers so that the 2 deployments with retention greater than $400 \mathrm{~d}$ have very little effect on the overall median. Lastly, it is possible that any tag head could provide reasonable retention success, as long as the entry wound is small, with minimal bleeding (Hallier \& Gaertner 2002, Prince et al. 2002).

The CPH model analyzing retention times indicated higher risk for early detachment of PSATs with the RD1500 device attached to the tether. If not restrained, the RD1500 might spin and fray the monofilament tether, thereby weakening it over time. Alternatively, the device could trigger PSAT detachment at a depth other than the specified threshold (Domeier et al. 2003). In addition, it is likely that the RD1500 might create turbulence and add extra drag to the tether and tag head, thereby promoting early release. Overall, MT PSATs were less likely to detach early than WC
PSATs. However, the RD1500 effects and manufacturer effects are confounded because the RD1500s were primarily associated with WC PSATs. Another plausible explanation for the RD1500-associated risk of early PSAT detachment - that would produce virtually identical retention results - would be a higher failure rate of nosecone pins on WC PSATs (Domeier et al. 2003, Stokesbury et al. 2004, Wilson et al. 2005, Domeier 2006). Unfortunately, there are no performance data on this part of the PSATs.

Tagging method (with the animal in the water versus restrained on deck) was not a significant factor in any of the $\mathrm{CPH}$ retention models when sharks and teleosts were pooled, but significantly influenced PSAT retention time when shark species were examined separately. Overall, tagging animals that are restrained on deck rather than tagging them in the water does not appear to be advantageous for increasing PSAT retention times. Thorsteinsson (2002) suggested that the extra handling of bringing an animal on deck introduces additional stress and promotes abrasion of the mucus layer, which could lead to fungal, bacterial, or viral infection. This might explain why animals tagged on deck (where tags can presumably be affixed with more precision) do not show greater PSAT retention. We originally assumed that the 'tagger' variable would capture important information on capture method, tagging method, platform, and handling procedures, but our results did not support this assumption. Random variability may have blocked any significant 'tagger effect'.

Great white sharks were the largest sample of sharks in the study $(\mathrm{n}=36)$ and the most successful in terms of PSAT retention time. They dominated the analysis and any grouping that included great white shark deployments had significantly better retention success than any other group without them. All 36 great white shark pop-up locations were above $15^{\circ} \mathrm{N}$, and the results from the shark retention model supported our general results from other $\mathrm{CPH}$ retention models indicating improved retention in cooler temperatures and in deeper habitat classes.

Sea turtles

Turtle species were pooled to increase sample size and because the differences in survival curves between species were not significantly different for PSAT retention. The best fitting model, using geographical region, showed that the California versus Hawaii comparison was significant, with the Hawaii PSAT deployments $\sim 4$ times more likely to detach prior to the programmed pop-up date. To learn more about turtle PSAT retention, we compared turtles to non-turtle species in the database with Kaplan-Meier survival curves 
and hazard functions. The survival curves intersected, indicating the involvement of different risk factors for PSAT retention. The hazard plot for PSAT deployments on non-turtles suggested an exponential hazard (bathtub) function, which is the assumed hazard function for most electronic devices (Allison 1995, Meeker \& Escobar 1998). However, if turtles had the same risk factors for tag retention as non-turtles, then the survival curves should be roughly the same shape.

Turtles had greater initial retention success, but then attachments failed at a much faster rate. The upwards trend in the turtle hazard function suggested that the risk factors accumulated over time. Examples of such additive risk factors are biofouling and degradation of the epoxy adhesive. By contrast, the non-turtle hazard function decreased slightly over time. Both hazard functions had sharp declines for very long retention times (>200 d). If a PSAT attachment survived for such a long time, it was likely to remain attached until the programmed pop-up date (a censored event, which also did not contribute to the hazard function).

In addition to the risk factors included in our analyses, marine turtle ecology and life history characteristics probably did not promote maximum PSAT retention times. As inhabitants of the surface mixed-layer (e.g. Swimmer et al. 2006), their ecology exposed them to increased concentrations of fouling organisms and debris. Social and sexual behavior could also have dislodged PSATs (Swimmer et al. 2002, 2006). Swimmer et al. (2002) demonstrated that PSATs attached to captive turtles with a foam base-plate and marine epoxy remained on the carapace for $>1$ yr. The base-plate attachment system was, however, specifically designed to detach should the PSAT became entangled.

\section{PSAT retention issues}

The combination of biological and non-biological factors in models suggests that variability in PSAT retention for pelagic species is a complex function influenced over spatial and temporal scales. Additional field variables would not necessarily help to clarify this situation, because some data would be exceedingly difficult (if not impossible) to quantify and/or were well beyond the scope of the study. For example, X-rays or magnetic resonance imaging would be needed to confirm that tag heads are wedged between pterygiophores. In the Hawaii data set for istiophorid billfish, the fish were quickly tagged in the water by harpoon, but data on e.g. fish size, tag placement, exhaustion, injury, and tag head insertion depth could not be accurately collected or are unknown. Moreover, without quantitative data on the stress and injury experienced by the animal, it is unclear if capture method (e.g. long- line, rod and reel, handline) would enhance our understanding of PSAT retention success. For example, to quantify levels of stress, factors such as fight time, time spent on the line, and biochemical indicators of morbidity and mortality would be needed (e.g. Moyes et al. 2006). As previously discussed ('Discussion - teleosts and sharks'), we attempted to account for some of the variability in PSAT retention by using an omnibus 'tagger' variable. Other factors (e.g. swimming speed of the tagged animal) could also have been important for retention, but they would need to be quantified by special instruments. PSATs are not equipped with impellers, so estimating speed through the water is not possible. Rather, it would be more appropriate to test these assumptions and others in controlled laboratory experiments, perhaps using flume tunnels. Once the effects of drag, vibration, and other vitiating forces of the PSATs and tethers can be estimated, it may be possible to explore other mechanical factors associated with retention success (e.g. fatigue of nosecone pins). It is highly probable that other factors are important to explain variability in PSAT retention, but until we can quantify these under controlled conditions, our models present the most parsimonious solutions.

\section{Data return}

Only about 1 of 10 PSAT deployments resulted in data return close to what was expected. Non-reporting PSATs severely reduced average data return, as did early detachment. Estimators of the fraction of missing data demonstrated that proportionally more data were lost through prematurely shed PSATs than through recording and Argos transmission failures. PSATs from both manufacturers had many gaps in the time series of data returned. Data like these can be challenging to interpret since most standard time series methods do not handle missing values well (Chatfield 1996). The scale of the horizontal axes for Fig. 8 was only 75 datadays since this was sufficient to capture the shape of the ECDFs, for PSATs from both manufacturers, even for deployments as long as $360 \mathrm{~d}$. Data density is an important measure of data quality because questions in ecology can require data on within-day behavior. If data density is $<1$ point $\mathrm{d}^{-1}$, then within-day behavior would not be captured, although information on dayto-day behavior and seasonal behavior might be adequate. For questions about within-day behavior and diel behaviour, it is clear that data acqisition intervals should be $<1 \mathrm{~h}$ (Table 4 ).

Regardless of manufacturer, estimating one geolocation per day requires both sunrise and sunset data. Therefore geolocation data return was considered directly comparable between the 2 manufacturers. 
Descriptive plots suggested that (1) more geolocation data were returned by PSATs in later production years because of improved reporting rates, (2) deployments on deeper-diving species returned fewer geolocation data due to lower reporting rates and/or possible problems recording surface light (Musyl et al. 2001, 2003, Dewar et al. 2011), and (3) MT PSATs returned more geolocation data than WC PSATs, perhaps because of more efficient data transmission schedules (MT PSATs broadcast data only when they are assumed to be in the footprint of Argos satellites instead of continuously). In addition, since the majority of tags were shed before their scheduled pop-up date, data priority schemes in WC PSATs may have favored broadcast of depth and temperature data over geolocation data (see 'Materials and methods - rationale for variable selection' [Variable 4]). Because data compression algorithms and transmission schedules to Argos are proprietary, we could not investigate data return rates in more detail.

\section{Models of optimal PSAT data return}

Summary statistics showed that data return was negatively correlated with habitat class and with the age of PSATs at the time of deployment. Data return was positively correlated with tag production year and the length of the pop-up period. However, only habitat class, tag production year, and the pop-up period were significant factors. The age of the PSAT at deployment was not influential after controlling for these more important explanatory variables. The decrease in data return with increasing habitat class suggests an influence of temperature and/or pressure on battery performance.

The return of geolocation data has improved for both manufacturers since 2000, and this appears attributable, at least in part, to an increased reporting rate. Model-predicted geolocation data overlaid on scatter plots (Fig. 9) of raw data showed that contour lines shifted upwards by year; this shift was based on the positive coefficient of the year variable in the equations (Table 5). The optimum values of pop-up period $\left(S^{*}\right)$ did not depend on year, however. Bootstrap analysis yielded smaller values of $S^{*}$ than did the models for geolocation data-days. This suggested bias was present in the Table 5 estimate of $S^{*}$ (Manly 2007). The bootstrap distributions provided a view of the actual sampling distribution for the estimator. Thus, the more conservative values of $S^{*}$ presented in Table 6 are preferable.

The development of the data return model followed a density dependence argument familiar to fisheries scientists (Quinn \& Deriso 1999). The expected number of data returned was assumed to be proportional to the pop-up period, with an exponential decline as the popup period increased. Three reasons account for this: (1) the cumulative probability of PSAT tag failure increased with the pop-up period, (2) communication and transmission of data to Argos became less certain as battery power decreased, and (3) biofouling increased with time and interfered with the antenna's ability to transmit data. The fitted curves of the data return models represent expected values of geolocation data-days, including failed PSATs, which appeared on the horizontal axis with zero data-days.

An alternative approach is to ignore deployments where the tag failed. Rerunning the models without the failed tags did not change the conclusions noticeably. Furthermore, tag failure must be accounted for when planning a sampling design. It is the cumulative risk of tag failure that is the key to understanding low average data return for especially long deployments $(>270 \mathrm{~d})$. Zero data return is one of the possible outcomes of a PSAT deployment and cannot be ignored when optimizing data return.

\section{Meta-analysis of PSAT performance}

Few published studies provided enough detailed information to examine retention time, percentage of data returned, or risk factors such as length of the popup period, tag age, and tag production year. Therefore, the only reasonable data to compare across species and studies were the reporting rates, which were indicated for all studies. However these data are not without problems; for example, publication bias would occur when results are not published because no PSATs reported or PSATs had a high failure rate. By contrast, reporting bias happens when authors publish their research without providing details on failed deployments. The latter would inflate the overall reporting rate and is more problematic. The database accumulated from the authors' research has no publication or reporting bias since it was not based on published articles.

The base of the funnel plot shape (Fig. 10) was widest for smaller sample sizes $(\mathrm{n}<10)$, implying larger variance in reporting rate when $\mathrm{n}$ was small. Asymmetry at the base of the funnel indicates that there was some publication bias. Thirty-two studies showed a $100 \%$ PSAT reporting rate with sample sizes between 1 and 20. Assuming (based on the authors' database) the overall PSAT reporting rate was $p=0.76$, then the probability of 10 PSATs reporting out of 10 deployments would be extremely low $\left(0.76^{10}=0.064\right)$. This suggests some author reporting bias was occurring, where authors only described successful deployments. 
PSAT reporting rates for individual species were not significantly different between the authors' database and the literature review in the epipelagic and mesopelagic I habitat classes (Table 8). In contrast, all individual mesopelagic II species comparisons significantly differed between the 2 data sources in terms of PSAT reporting rates. But when pooled, the mesopelagic II group did not exhibit significantly different reporting rates between the data sources. Such contradictory results provide an example of Simpson's paradox (Agresti 2002), and the paradox is resolved when the direction of the effect size and the relative sample sizes of the species involved are considered. Bluefin tuna comprised one of the groups with the largest sample sizes in both the authors' database $(n=146)$ and the literature review $(n=549)$ and showed a significant difference in PSAT reporting rates between the database and literature review (86 vs. $78 \%$, respectively); all other mesopelagic II species, however, had significantly higher reporting rates in the literature review. The relative weight of the bluefin tuna effect counterbalanced the effect of the combined other mesopelagic II species when considered as one mesopelagic II group.

Bootstrap analysis and log likelihood ratio tests that were derived from data in published studies suggested that increasing habitat class decreased the PSAT reporting rate. Independently, logistic regression reporting models constructed from the authors' database showed the same. Publication year was a significant factor within the literature review and indicated that reporting rates have decreased over time. However, one caveat about 'year' in this instance is that publication year (of the journal article) was used instead of tag production year which was not reported in published articles. Publication year probably followed deployment by several years, while tag production year preceded deployment by 6 mo to $1 \mathrm{yr}$.

\section{Fault tree of PSAT failure modes}

The PSAT fault tree (Fig. 1) was designed largely as a model to explain possible outcomes of PSAT deployments in order to design specific experiments that address questions about PSAT failure and early detachment. Fault tree methodology has proved to be a useful analytical tool in areas as diverse as SCUBA diving accidents (Tetlow 2006) and failures of lithium batteries (Bowers \& Hardy 2006). Our task was challenging since we had no performance information on nonreporting PSATs (i.e. we had to work from the top of the tree downwards). The PSAT fault tree we constructed was not unique, but a binary tree has desirable logical advantages. PSAT retention and reporting rates were assumed to be independent events and by implication that non-reporting PSATs have similar retention outcomes. Tag retention questions could then be considered separately from questions about non-reporting PSATs. A caution here is that some events show up on both sides of the tree. For example, animal mortality might result in early PSAT detachment as the body sinks, or it might result in reporting failure if the PSAT was destroyed by pressure or predation. Lastly, human error was not indicated on this tree, although it is apparent that tag programming and deployment errors could cause early detachment, low data return, and complete failure (e.g. Seitz et al. 2003). Some branches of the tree could be pruned by accelerated life tests (ALT) (Meeker \& Escobar 1998). For example, if pressure is thought to be a risk factor, the PSATs could be repeatedly cycled to extreme depths to simulate typical diving behavior of pelagic animals. Similarly, ALT experiments could be used to test for PSAT battery failure under variable temperature and pressure regimes (Ratnakumar et al. 2000, Bowers \& Hardy 2006, Loud \& Hu 2007, Mikolajczak et al. 2007).

\section{General summary and recommendations}

PSATs deployed on deep-diving (mesopelagic) species were more likely to fail than those on epipelagic species. However, this pattern was strongly influenced by habitat class, temperature, and tag production year. Prior knowledge of how reporting rates are affected by these 3 factors is therefore important in the context of optimizing sampling design. Use of sample size multipliers (i.e. the ratio of the number of PSAT deployed to the number of PSATs reporting data) is recommended for future PSAT sample designs, ranging from 1.0 for the epipelagic green turtle to 2.7 for the mesopelagic II bigeye thresher shark (Table S6 in the supplement at www.int-res.com/articles/suppl/m433p001_supp. pdf). Although data from the literature review could contain reporting and publication biases, sample size multipliers from this source were also included as it is the best information available for some species.

Risk factors for habitat class and pressure (and/or temperature) had opposite effects on PSAT performance. For example, increasing habitat class reduced reporting rate and data return, but increased retention time, which possibly indicates some unspecified pressure or temperature induced reporting failure mechanism(s). These same factors, however, were also probably advantageous for retention by creating an environment not conducive for fouling organisms.

Of the various risk factors analyzed for tag retention, biofouling and infection are probably the most important problems researchers need to address. The use of 
newer antimicrobial agents containing silver nanoparticles (Kumar et al. 2008, Zodrow et al. 2009) or possibly myrrh-derived terpenoids (Pope et al. 2008) on PSATs could reduce biofouling. Researchers are advised to routinely disinfect the anchor, tether, and tag applicator prior to PSAT insertion so that infections at the PSAT attachment site are minimized. In parallel, the use of time-delayed antibiotics (e.g. Daniel et al. 2008) and broad-spectrum bactericides could reduce microbial invasion, promote wound healing, and thus reduce infection, tissue necrosis, and premature PSAT shedding. Moreover, swimming speed (particularly burst swimming common in some pelagic species), body size and shape relationships, and tag placement are probably important factors in terms of tag retention, but we have no performance data for these situations. Furthermore, we have no quantitative data on optimal tether length, diameter and material. These factors could be tested in flume tunnels (Grusha \& Patterson 2005) to see which combination(s) minimizes tag movement (e.g. precession) and drag for different species. The biggest gains in data return that manufacturers can provide are longer battery life, batteries and components less likely to fail following repeated changes in pressure and temperature, and more efficient data transmission schedules to Argos.

Lastly, researchers need to continue to determine which PSAT design will best fit their experimental design and the goals of their research. Continued monitoring of tag performance should make this task easier. The PSATs from 2 manufactures featured in this study have different strengths and weaknesses in terms of reporting, retention, and data return. The tags from WC offer user programming and data download procedures, but the satellite data are summarized as histograms and PDTs (unless the PSAT is retrieved). PSATs from MT record and store raw data in time series, and data recovery procedures are maximized by their proprietary data transmission algorithms. PSAT technology is, however, rapidly changing. Both WC and MT now offer smaller PSATs that can be deployed on smaller species. Lastly, there are now 2 additional PSAT manufacturers on the market: Desert Star Systems and Lotek.

Acknowledgements. This project was funded by Cooperative Agreements NA37RJ0199 and NA67RJ0154 from the National Oceanic and Atmospheric Administration (NOAA) with the Joint Institute for Marine and Atmospheric Research (JIMAR), University of Hawaii. Mahalos to J. Sibert and D. Lau, Pelagic Fisheries Research Program, JIMAR, and to C. Boggs and K. Bigelow, NOAA Pacific Islands Fisheries Science Center, Honolulu (HI) for their support of the project. A. $\mathrm{Au}$, head librarian at PIFSC, provided exceptional help with tracking down obscure reports and articles, which was greatly appreciated. C. Boggs, K. Bigelow and B. Walsh pro- vided comments on an early draft and J. Sibert, K. Holland, M. McCracken, T. Quinn and B. Meeker offered suggestions that improved the study. Four anonymous referees made constructive comments that improved the manuscript.

Disclaimer. The authors or their agencies do not necessarily approve, recommend, or endorse any proprietary hardware or software mentioned in this publication. The views expressed herein are those of the authors and do not necessarily reflect the views of their agencies.

\section{LITERATURE CITED}

Adams DC, Gurevitch J, Rosenburg MS (1997) Resampling tests for meta-analysis of ecological data. Ecology (USA) $78: 1277-1283$

Agresti A (2002) Categorical data analysis, 2nd edn. Wiley, Hoboken, NJ

Allison P (1995) Survival analysis using SAS: a practical guide. SAS Press, Cary, NC

Argos (2007) A few hints on using ARGOS in Europe. ARGOS Forum 63:16

Arnold G, Dewar H (2001) Electronic tags in marine fisheries research: a 30-year perspective. In: Sibert JR, Nielsen JL (eds) Electronic tagging and tracking in marine fisheries reviews: methods and technologies in fish biology and fisheries. Kluwer Academic Press, Dordrecht, p 7-64

Benson SR, Dutton PH (2005) Evaluation of pop-up archival transmitters to determine cause of failure for satellite transmitters deployed on Pacific leatherback turtles. In: Sheridan P, Ferguson JW, Downing SL (eds) Report of the national marine fisheries service workshop on advancing electronic tag technology and their use in stock assessments. NOAA Tech Memo, NMFS-F/SPO-82. US Department of Commerce, Washington, DC, p 21-22

Bernal D, Sepulveda C, Musyl M, Brill R (2009) The eco-physiology of swimming and movement patterns of tunas, billfishes and large pelagic sharks. In: Domenici P, Kapoor, BG (eds) Fish locomotion - an etho-ecological approach. Enfield Scientific Publishers, Enfield, NH, p 437-483

Bestley S, Gunn JS, Hindell MA (2009) Plasticity in vertical behaviour of migrating juvenile southern bluefin tuna (Thunnus maccoyii) in relation to oceanography of the south Indian Ocean. Fish Oceanogr 18:237-254

Block BA, Dewar H, Farwell C, Prince ED (1998) A new satellite technology for tracking the movements of Atlantic bluefin tuna. Proc Natl Acad Sci USA 95:9384-9389

Bolle LJ, Hunter E, Rijnsdorp AD, Pastoors MA, Metcalfe JD, Reynolds JD (2005) Do tagging experiments tell the truth? Using electronic tags to evaluate conventional tagging data. ICES J Mar Sci 62:236-246

Borucinska J, Martin J, Skomal G (2001) Peritonitis and pericarditis associated with gastric perforation by a retained fishing hook in a blue shark. J Aquat Anim Health 13: 347-354

Borucinska J, Kohler N, Natanson L, Skomal G (2002) Pathology associated with retained fishing hooks in blue shark, Prionace glauca (L.), with implications for their conservation. J Fish Dis 25:515-521

Bowers JS, Hardy DB (2006) Fault tree analysis of prismatic lithium thionyl chloride $\left(\mathrm{Li} / \mathrm{SOCl}_{2}\right)$ battery cells - phase 1 . IEEE Xplore 21: 1276-1279

Brill R, Lutcavage M (2001) Understanding environmental influences on movements and depth distributions of tunas and billfishes can significantly improve population assessments. In: Sedberry G (ed) Islands in the stream: oceanog- 
raphy and fisheries of the Charleston Bump. Am Fish Soc Symp 25:179-198

Brill RW, Bigelow KA, Musyl MK, Fritsches KA, Warrant EJ (2005) Bigeye tuna (Thunnus obesus) behavior and physiology and their relevance to stock assessments and fishery biology. Collect Vol Sci Pap ICCAT 57:142-161

> Cannon MD, Edmondson AC (2005) Failing to learn and learning to fail (intelligently): how great organizations put failure to work to improve and innovate. Long Range Plann 38:299-319

Chaloupka M, Parker D, Balazs G (2004) Modelling postrelease mortality of loggerhead sea turtles exposed to the Hawaii-based pelagic longline fishery. Mar Ecol Prog Ser 280:285-293

Chaprales W, Lutcavage M, Brill R, Chase B, Skomal G (1998) Harpoon method for attaching ultrasonic and 'popup' satellite tags to giant bluefin tuna and large pelagic fishes. Mar Technol Soc J 32:104-105

Chatfield C (1996) The analysis of time series - an introduction, 5th edn. Chapman \& Hall, London

Cox DR (1972) Regression models and life tables (with discussion). JR Stat Soc B34:187-220

Daniel AJ, Hicks BJ, Ling N, David B (2008) Retention of acoustic and radio transmitters in New Zealand koi carp (Cyprinus carpio). Advances in fish tagging and marking technology, Int Symp, February 2008, Auckland, New Zealand. American Fisheries Society, Bethesda, MD, p 59 (Abstract)

De Metrio G, Arnold GP, de la Serna JM, Yannopoulos C, Megalofonou P, Buckley AA, Pappalepore M (2001) Further results of tagging Mediterranean bluefin tuna with pop-up satellite-detected tags. Collect Vol Sci Pap ICCAT 52:776-783

De Metrio G, Arnold GP, Block BA, de la Serna JM and others (2002) Behavior of post-spawning Atlantic bluefin tuna tagged with pop-up satellite tags in the Mediterranean and Eastern Atlantic. Collect Vol Sci Pap ICCAT 54:415-424

De Metrio GD, Oray I, Arnold GP, Lutcavage M and others (2004) Joint Turkish-Italian research in the eastern Mediterranean: bluefin tuna tagging with pop-up satellite tags. Collect Vol Sci Pap ICCAT 56:1163-1168

De Metrio GD, Arnold GP, de la Serna JM, Block BA and others (2005) Movements of bluefin tuna (Thunnus thynnus L.) tagged in the Mediterranean Sea with pop-up satellite archival tags. Collect Vol Sci Pap ICCAT 58:1337-1339

> Dewar H, Prince DE, Musyl MK, Brill RW and others (2011) Movements and behaviors of swordfish in the Atlantic and Pacific Oceans examined using pop-up satellite archival tags. Fish Oceanogr 20:219-241

Domeier ML (2006) An analysis of Pacific striped marlin (Tetrapturus audax) horizontal movement patterns using pop-up satellite archival tags. Bull Mar Sci 79:811-825

> Domeier ML, Nasby-Lucas N (2008) Migration patterns of white sharks Carcharodon carcharias tagged at Guadalupe Island, Mexico, and identification of an eastern Pacific shared offshore foraging area. Mar Ecol Prog Ser 370:221-237

Domeier ML, Dewar H, Nasby-Lucas N (2003) Mortality rate of striped marlin (Tetrapturus audax) caught with recreational tackle. Mar Freshw Res 54:435-445

Domeier ML, Kiefer D, Nasby-Lucas N, Wagschal A, O'Brien F (2005) Tracking Pacific bluefin (Thunnus thynnus orientalis) in the northeastern Pacific with an automated algorithm that estimates latitude by matching sea-surface temperature data from satellites with temperature data from tags on fish. Fish Bull 103:292-306

Donders A, van der Heijden G, Stijnen T, Moons K (2006)
Review: a gentle introduction to imputation of missing values. J Clin Epidemiol 59:1087-1091

Epperly SP, Wyneken J, Flanagan JP, Harms CA, Higgins B (2007) Attachment of pop-up archival transmitting (PAT) tags to loggerhead sea turtles (Caretta caretta). Herpetol Rev 38:419-425

Fredriksson D, Reichel J, Waters R, Fragoso N, Lutcavage M (2007) A hydrodynamic analysis of popup satellite archival tags used for tracking marine species. Second Int Symp on Tagging and Tracking Marine Fish with Electronic Devices, October 8-11, 2007, Donostia-San Sebastián, Spain. Large Pelagics Research Center, University of New Hampshire, Durham, NH, p 94 (Abstract)

> Furuya K (1990) Subsurface chlorophyll maximum in the tropical and substropical Pacific Ocean: vertical profiles of phytoplankton biomass and its relationship with chlorophyll $a$ and particulate organic carbon. Mar Biol 107: 529-539

Galuardi B, Nielsen A, Lutcavage M (2008) Optimizing smoothed sea surface temperature for improving archival tag geolocation. Mar Ecol Prog Ser 365:35-44

Gaspar P, Malardé JP (2007) Analysis of Argos system performance in the Mediterranean area for transmitters with weak output power such as pop-up tags. Second Int Symp on Tagging and Tracking Marine Fish with Electronic Devices, October 8-11, 2007, Donostia-San Sebastián, Spain. Large Pelagics Research Center, University of New Hampshire, Durham, NH, p 94 (Abstract)

Gilly WF, Markaida U, Baxter CH, Block BA and others (2006) Vertical and horizontal migrations by the jumbo squid Dosidicus gigas revealed by electronic tagging. Mar Ecol Prog Ser 324:1-17

Goodyear CP (2002) Factors affecting robust estimates of the catch-and-release mortality using pop-off tag technology. Am Fish Soc Symp 30:172-179

Graves JE, Luckhurst BE, Prince ED (2002) An evaluation of pop-up satellite tags for estimating postrelease survival of blue marlin (Makaira nigricans) from a recreational fishery. Fish Bull 100:134-142

Gros P, Malardé JP, Woodward B (2006) Argos performance in Europe, Part 2. Tracker News 7:8

Grusha DS, Patterson MR (2005) Quantification of drag and lift imposed by pop-up satellite archival tags and estimation of the metabolic cost to cownose rays (Rhinoptera bonasus). Fish Bull 103:63-70

Gunn J, Block B (2001) Advances in acoustic, archival, and satellite tagging of tunas. In: Block BA, Stevens ED (eds) Tuna physiology, ecology, and evolution. Academic Press, New York, NY, p 167-224

Gunn JS, Patterson TA, Pepperell JG (2003) Short-term movement and behavior of black marlin Makaira indica in the Coral Sea as determined through a pop-up satellite archival tagging experiment. Mar Freshw Res 54:515-525

> Gurevitch J, Hedges LV (1999) Statistical issues in ecological meta-analyses. Ecology (USA) 80:1142-1149

Hallier JP, Gaertner D (2002) Comparative efficiency between BETYP tags and conventional tags. Collect Vol Sci Pap ICCAT 54:17-32

Hays GC, Bradshaw CJA, James MC, Lovell P, Sims DW (2007) Why do Argos satellite tags deployed on marine animals stop transmitting? J Exp Mar Biol Ecol 349:52-60

Hedgpeth JW (1957) Classification of marine environments. In: Hedgpeth JW (ed) Treatise on marine ecology and paleoecology, Vol 1, Ecology. Geol Soc Amer Mem 67: $17-28$

Holland KN, Braun MJ (2003) Proceedings of 'tying one on'a workshop on tag attachment techniques for large marine 
animals. Honolulu, HI, 4-5 December 2002. School of Ocean and Earth Science and Technology (SOEST) publ. no. 03-02. Joint Institute for Marine and Atmospheric Research Contribution (JIMAR) 03-349. www.soest.hawaii. edu/PFRP/soest_jimar_rpts/holland_braun.pdf (Accessed 13 February 2008)

Hosmer DW, Lemeshow S (1989) Applied logistic regression. Wiley, New York, NY

Howey P (2005) Argos Performance in Europe. Tracker News $2: 8$

Jellyman D, Tsukamoto K (2002) First use of archival transmitters to track migrating freshwater eels Anguilla dieffenbachii at sea. Mar Ecol Prog Ser 233:207-215

Jennrich RI (1994) An introduction to computational statistics: regression analysis. Prentice Hall, Inglewood Cliffs, NJ

Johnson FH, Eyring H, Stover BJ (1974) The theory of rate processes in biology and medicine. Wiley, New York, NY

Kerstetter DW, Graves JE (2006) Survival of white marlin (Tetrapturus albidus) released from commercial longline gear in the western North Atlantic. Fish Bull 104:434-444

Kerstetter DW, Luckhurst BE, Prince ED, Graves JE (2003) Use of pop-up satellite archival tags to demonstrate survival of blue marlin (Makaira nigricans) released from pelagic longline gear. Fish Bull 101:939-948

Kerstetter DW, Polovina JJ, Graves JE (2004) Evidence of shark predation and scavenging on fishes equipped with pop-up satellite archival tags. Fish Bull 102:750-756

Kumar A, Vemula PK, Ajayan PJ, John G (2008) Silvernanoparticle-embedded antimicrobial paints based on vegetable oil. Nat Mater (7):236-241

Longhurst A (1998) Ecological geography of the sea. Academic Press, San Diego, CA

Loud J, Hu X (2007) Failure analysis methodology for Li-ion incidents. In: ISTFA 2007: Proc 33rd Int Symp for Testing and Failure Analysis, November 4-8, 2007, San Jose, CA. AMS International, Materials Park, OH, p 242-261

Luo J, Ault JS, Larkin MF, Barbieri LR (2008) Salinity measurements from pop-up archival transmitting (PAT) tags and their application to geolocation estimation for Atlantic tarpon. Mar Ecol Prog Ser 357:101-109

Lutcavage ME, Brill RW, Skomal GB, Chase BC, Howey PW (1999) Results of pop-up satellite tagging of spawning size class fish in the Gulf of Maine: Do North Atlantic bluefin tuna spawn in the mid-Atlantic? Can J Fish Aquat Sci 56: 173-177

Lutcavage M, Rhodin AGJ, Sandove SS, Conroy CR (2001) Direct carapacial attachment of satellite tags using orthopedic bioabsorbable mini-anchor screws on leatherback turtles in Culebra, Puerto Rico. Mar Turtle Newsl 95:9-12

Manly B (2007) Randomization, bootstrap and Monte Carlo methods in biology. CRC Press, Boca Rotan, FL

Marshall HG (1966) Observations on the vertical distribution of coccolithophores in the northwestern Sargasso Sea. Limnol Oceanogr 11:432-435

Meeker WQ, Escobar LA (1998) Statistical methods of reliability data. Wiley, New York, NY

Meng XL (2000) Missing data: dial M for ??? J Am Stat Assoc 95:1325-1330

Mikolajczak CJ, Hayes T, Megerle MV, Wu M (2007) A scientific methodology for investigation of a lithium ion battery failure. IEEE Portable 2007 - Int Conf on Portable Information Devices, IEEE report no. 1-4244-1039-8/07, Orlando, FL, 25-29 March 2007. IEEE, New York, NY, p 1-6

> Moyes CD, Fragoso N, Brill RW, Musyl MK (2006) Predicting postrelease survival in large pelagic fish. Trans Am Fish Soc 135:1389-1397

Musyl MK, Brill RW, Curran DS, Gunn JS and others (2001)
Ability of archival tags to provide estimates of geographical position based on light intensity. In: Sibert J, Nielsen J (eds) Electronic tagging and tracking in marine fisheries reviews: methods and technologies in fish biology and fisheries. Kluwer Academic Press, Dordrecht, p 343-368

> Musyl MK, Brill RW, Boggs CH, Curran DS, Kazama TK, Seki MP (2003) Vertical movements of bigeye tuna (Thunnus obesus) associated with islands, buoys, and seamounts near the main Hawaiian Islands from archival tagging data. Fish Oceanogr 12:152-169

Musyl MK, McNaughton LM, Swimmer JY, Brill RW (2004) Convergent evolution of vertical movement behavior in swordfish, bigeye tuna and bigeye thresher sharks. Vertical niche partitioning in the pelagic environment as shown by electronic tagging studies. PFRP Newsletter 9(4):1-4

Musyl MK, Brill RW, Curran DS, Fragoso NM and others (2011) Post-release survival, vertical and horizontal movements, and thermal habitats of five species of pelagic sharks in the central Pacific Ocean. Fish Bull (in press)

Myers RH, Douglas CM, Vining GG (2002) Generalized linear models with applications in engineering and the sciences. Wiley, New York, NY

NMFS (National Marine Fisheries Service) (1994) Archival tags 1994: present and future. NOAA Tech Memo, NMFSSEFSC-357. US Department of Commerce, Washington, DC

Neilson JD, Smith S, Royer F, Paul SD, Porter JM, Lutcavage $M$ (2009) Investigations of horizontal movements of Atlantic swordfish using pop-up satellite archival tags. In: Nielsen JL, Arrizabalaga H, Fragoso N, Hobday A, Lutcavage $M$, Sibert J (eds) Reviews: methods and technologies in fish biology and fisheries. Tagging and tracking of marine animals with electronic devices. Kluwer Academic Press, Dordrecht, p 145-159

Nielsen A, Bigelow KA, Musyl MK, Sibert JR (2006) Improving light-based geolocation by including sea surface temperature. Fish Oceanogr 15:314-325

Parin NV (1970) Ichthyofauna of the epipelagic zone. US Department of Interior and National Science Foundation, Washington, DC

Pérez V, Fernández E, Marañón E, Morán XAG, Zubkov MV (2006) Vertical distribution of phytoplankton biomass, production and growth in the Atlantic subtropical gyres. Deep-Sea Res I 53:1616-1634

Polovina JJ, Hawn D, Abecassis M (2007) Vertical movement and habitat of opah (Lampris guttatus) in the central North Pacific recorded with pop-up archival tags. Mar Biol 153: 257-267

Pope DH, Berger LR (1973) Algal photosynthesis at increased hydrostatic pressure and constant $p \mathrm{O}_{2}$. Arch Microbiol 4: 321-325

Pope EC, Ali A, Conlan SL, Bowen ID, Clare AS, Rowley AF (2008) Myrrh-derived terpenoids as inhibitors of marine biofouling. Aquat Biol 4:175-185

Prince ED, Ortiz M, Venizelos A, Rosenthal DS (2002) Inwater conventional tagging techniques developed by the Cooperative Tagging Center for large, highly migratory species. In: Lucy JA, Studholme AL (eds) Catch and release in marine recreational fisheries. Am Fish Soc Symp 30:155-171

Quinn TJ, Deriso RB (1999) Quantitative fish dynamics. Oxford University Press, New York, NY

> Ramesh KB (2000) Dependence of $\mathrm{SSN}_{M}$ on $\mathrm{SSN}_{m}$ - a reconsideration for predicting the amplitude of a sunspot cycle. Sol Phys 197:421-424

Ratnakumar BV, Smart MC, Huang CK, Perrone D, Surampudi S, Greenbaum SG (2000) Lithium ion batteries for Mars exploration missions. Electrochim Acta 45:1513-1517 
Rice JA (1995) Mathematical statistics and data analysis. International Thompson Publishing, Belmont, CA

Roberts RJ, MacQueen A, Shearer WM, Young H (1973a) The histopathology of salmon tagging. I. The tagging lesion in newly tagged parr. J Fish Biol 5:497-503

Roberts RJ, MacQueen A, Shearer WM, Young H (1973b) The histopathology of salmon tagging. II. The chronic tagging lesion in returning adult fish. J Fish Biol 5:615-619

Roberts RJ, MacQueen A, Shearer WM, Young H (1973c) The histopathology of salmon tagging. III. Secondary infections associated with tagging. J Fish Biol 5:621-623

Ryder CE, Conant TA, Schroeder BA (2006) Report of the workshop on marine turtle longline post-interaction mortality. NOAA Technical Memorandum NMFS-F/OPR-29. US Department of Commerce, Washington, DC

Sasso CR, Epperly SP (2007) Survival of pelagic juvenile loggerhead turtles in the open ocean. J Wildl Manag 71: 1830-1835

Schaefer KM, Fuller DW, Block BA (2007) Movements, behavior, and habitat utilization of yellowfin tuna (Thunnus albacares) in the northeastern Pacific Ocean, ascertained through archival tag data. Mar Biol 152:503-525

Sedberry GR, Loefer JK (2001) Satellite telemetry tracking of swordfish, Xiphias gladius, off the eastern United States. Mar Biol 139:355-360

Seitz AC, Wilson D, Norcross BL, Nielsen JL (2003) Pop-up archival transmitting (PAT) tags: a method to investigate the migration and behavior of Pacific halibut, Hippoglossus stenolepis in the Gulf of Alaska. Alsk Fish Res Bull 10: 124-136

Seki MP, Polovina JJ, Kobayashi DR, Bidigare RR, Mitchum GT (2002) An oceanographic characterization of swordfish (Xiphias gladius) longline fishing grounds in the springtime subtropical North Pacific. Fish Oceanogr 11:251-266

Sibert JR, Lutcavage ME, Nielsen A, Brill RW, Wilson SG (2006) Interannual variation in large-scale movement of Atlantic bluefin tuna (Thunnus thynnus) determined from pop-up satellite archival tags. Can J Fish Aquat Sci 63: 2154-2166

Stokesbury MJW, Teo SLH, Seitz A, O'Dor RK, Block BA (2004) Movement of Atlantic bluefin tuna (Thunnus thynnus) as determined by satellite tagging experiments initiated off New England. Can J Fish Aquat Sci 61:1976-1987

Swimmer Y, Brill R, Musyl M (2002) Use of pop-up satellite archival tags to quantify mortality in marine turtles incidentally captured in longline fishing gear. Mar Turtle Newsl 97:3-7

Swimmer Y, Arauz R, McCracken M, McNaughton L and others (2006) Diving behavior and delayed mortality of olive ridely sea turtles Lepidochelys olivacea after their release from longline fishing gear. Mar Ecol Prog Ser 323:253-261

Teo SLH, Boustany A, Blackwell S, Walli A, Weng KC, Block BA (2004) Validation of geolocation estimates based on light level and sea surface temperature from electronic tags. Mar Ecol Prog Ser 283:81-98

Tetlow S (2006) Formal risk identification in professional

Editorial responsibility: Matthias Seaman,

Oldendorf/Luhe, Germany
SCUBA (FRIPS). Research report no. 436. Health and Safety Executive, Her Majesty's Stationary Office, Norwich

Thorsteinsson V (2002) Tagging methods for stock assessment and research in fisheries. Report of Concerted Action FAIR CT.96.1394 (CATAG). Technical Report no. 79. Marine Research Institute, Reykjavik

Trent JD, Yayanos AA (1985) Pressure effects on the temperature range for growth and survival of the marine bacterium Vibrio harveyi: implications for bacteria attached to sinking particles. Mar Biol 89:165-172

> Watkins WA (1979) A projectile point for penetrating whale blubber. Deep-Sea Res A 26:1301-1308

Weng KC, Boustany AM, Pyle P, Anderson SD, Brown A, Block BA (2007) Migration and habitat of white sharks (Carcharodon carcharias) in the eastern Pacific Ocean. Mar Biol 152:877-894

Westerberg H, Eveson P, Welch D, Karlsson L, Ikonen E (1999) Data storage tag study of salmon (Salmo salar) migration in the Baltic: the performance of tags. ICES Ann Sci Conf, CM 1999/AA:07 (mimeo)

Whitehead PJP, Vergara R (1978) Megalopidae. In: Fischer W (ed) FAO species identification sheets for fishery purposes, Western Central Atlantic (Fishing Area 31), vol 3. FAO, Rome

Wildlife Computers (2006) PAT4 user guide. 17 February 2006, Redmond, WA. www.wildlifecomputers.com/Downloads/ Documentation/PAT4\%20Manual.pdf (Accessed 25 April 2011)

> Wilson SG, Lutcavage ME, Brill RW, Genovese MP, Cooper AB, Everly AW (2005) Movements of bluefin tuna (Thunnus thynnus) in the northwestern Atlantic Ocean recorded by pop-up satellite archival tags. Mar Biol 146:409-423

Wilson SG, Polovina JJ, Stewart BS, Meekan MG (2006) Movements of whale sharks (Rhincodon typus) tagged at Nigaloo Reef, Western Australia. Mar Biol 148:1157-1166

> Wilson SG, Stewart BS, Polovina JJ, Meekan MG, Stevens JD, Galuardi B (2007) Accuracy and precision of archival tag data: a multiple-tagging study conducted on a whale shark (Rhincodon typus) in the Indian Ocean. Fish Oceanogr 16:547-554

Yayanos AA, Boxtel RV, Dietz AS (1983) Reproduction of Bacillus stearothermophilus as a function of temperature and pressure. Appl Environ Microbiol 46:1357-1363

Zar JH (1996) Biostatistical analysis, 3rd edn. Prentice Hall, Upper Saddle River, NJ

Zobell CE, Johnson FH (1949) The influence of hydrostatic pressure on the growth and viability of terrestrial and marine bacteria. J Bacteriol 57:179-189

Zobell CE, Oppenheimer CH (1950) Some effects of hydrostatic pressure on the multiplication and morphology of marine bacteria. J Bacteriol 60:771-781

Zodrow K, Brunet L, Mahendra S, Li D, Zhang A, Li Q, Alvarez PJJ (2009) Polysulfone ultrafiltration membranes impregnated with silver nanoparticles show improved biofouling resistance and virus removal. Water Res 43: $715-723$

Submitted: July 23, 2010; Accepted: May 5, 2011

Proofs received from author(s): June 27, 2011 